\title{
The thiosemicarbazone $\mathrm{Me}_{2} \mathrm{NNMe}_{2}$ induces paraptosis by disrupting the ER thiol redox homeostasis based on protein disulfide isomerase inhibition
}

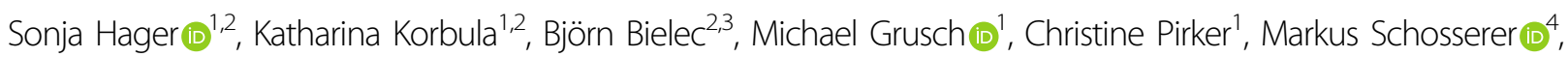 \\ Lisa Liendl ${ }^{4}$, Magdalena Lang ${ }^{4}$, Johannes Grillari, ${ }^{4,5,6}$, Karin Nowikovsky ${ }^{7}$, Veronika F. S. Pape ${ }^{8,9}$, Thomas Mohr ${ }^{1,10}$, \\ Gergely Szakács ${ }^{1,9}$, Bernhard K. Keppler ${ }^{2,3}$, Walter Berger [1 ${ }^{1,2}$, Christian R. Kowol ${ }^{2,3}$ and Petra Heffeter ${ }^{1,2}$
}

\begin{abstract}
Due to their high biological activity, thiosemicarbazones have been developed for treatment of diverse diseases, including cancer, resulting in multiple clinical trials especially of the lead compound Triapine. During the last years, a novel subclass of anticancer thiosemicarbazones has attracted substantial interest based on their enhanced cytotoxic activity. Increasing evidence suggests that the double-dimethylated Triapine derivative $\mathrm{Me}_{2} \mathrm{NNMe}_{2}$ differs from Triapine not only in its efficacy but also in its mode of action. Here we show that $\mathrm{Me}_{2} \mathrm{NNMe}_{2}$ (but not Triapine)-treated cancer cells exhibit all hallmarks of paraptotic cell death including, besides the appearance of endoplasmic reticulum (ER)-derived vesicles, also mitochondrial swelling and caspase-independent cell death via the MAPK signaling pathway. Subsequently, we uncover that the copper complex of $\mathrm{Me}_{2} \mathrm{NNMe}_{2}$ (a supposed intracellular metabolite) inhibits the ER-resident protein disulfide isomerase, resulting in a specific form of ER stress based on disruption of the $\mathrm{Ca}^{2+}$ and ER thiol redox homeostasis. Our findings indicate that compounds like $\mathrm{Me}_{2} \mathrm{NNMe}_{2}$ are of interest especially for the treatment of apoptosis-resistant cancer and provide new insights into mechanisms underlying drug-induced paraptosis.
\end{abstract}

\section{Introduction}

$\alpha-N$-Heterocyclic thiosemicarbazones (TSCs) are a promising class of therapeutics, which have been extensively investigated for their anticancer activity ${ }^{1,2}$. The most prominent and best-studied drug candidate is 3aminopyridine-2-carboxaldehyde TSC, also known as Triapine. Triapine displayed promising results in clinical phase I and II trials against hematological cancers ${ }^{3-6}$ and has also been tested against diverse solid tumors ${ }^{7,8}$. In

\footnotetext{
Correspondence: Petra Heffeter (petra.heffeter@meduniwien.ac.at) ${ }^{1}$ Institute of Cancer Research and Comprehensive Cancer Center, Department of Medicine I, Medical University of Vienna, Borschkegasse 8a, A-1090 Vienna, Austria

${ }^{2}$ Research Cluster "Translational Cancer Therapy Research", Vienna, Austria Full list of author information is available at the end of the article. Edited by: P. Salomoni
}

addition, several new TSC derivatives have been developed over the last years. Two of them, namely Coti- 2 and $\mathrm{DpC}$, have recently entered clinical phase I trials (www. clinicaltrials.gov). Coti-2, $\mathrm{DpC}$ as well as the predecessor Dp44mT showed highly improved anticancer activities compared to Triapine with $\mathrm{IC}_{50}$ values in the nanomolar concentration range (hence, called "nanomolar TSCs") , $^{\text {,10 }}$. Our group has recently synthesized a new nanomolar TSC derivative, $\mathrm{Me}_{2} \mathrm{NNMe}_{2}$, characterized by dimethylation of both primary amino groups of the Triapine molecule(Fig. 1) 2,11. $^{2}$.

Based on promising clinical trials, it is of interest to better elucidate the reasons for the greatly improved anticancer activity of nanomolar TSCs. There are several indications that nanomolar TSCs differ in their mode of

\section{(c) The Author(s) 2018}

(c) (i) Open Access This article is licensed under a Creative Commons Attribution 4.0 International License, which permits use, sharing, adaptation, distribution and reproduction cc) in any medium or format, as long as you give appropriate credit to the original author(s) and the source, provide a link to the Creative Commons license, and indicate if changes were made. The images or other third party material in this article are included in the article's Creative Commons license, unless indicated otherwise in a credit line to the material. If material is not included in the article's Creative Commons license and your intended use is not permitted by statutory regulation or exceeds the permitted use, you will need to obtain permission directly from the copyright holder. To view a copy of this license, visit http://creativecommons.org/licenses/by/4.0/. 


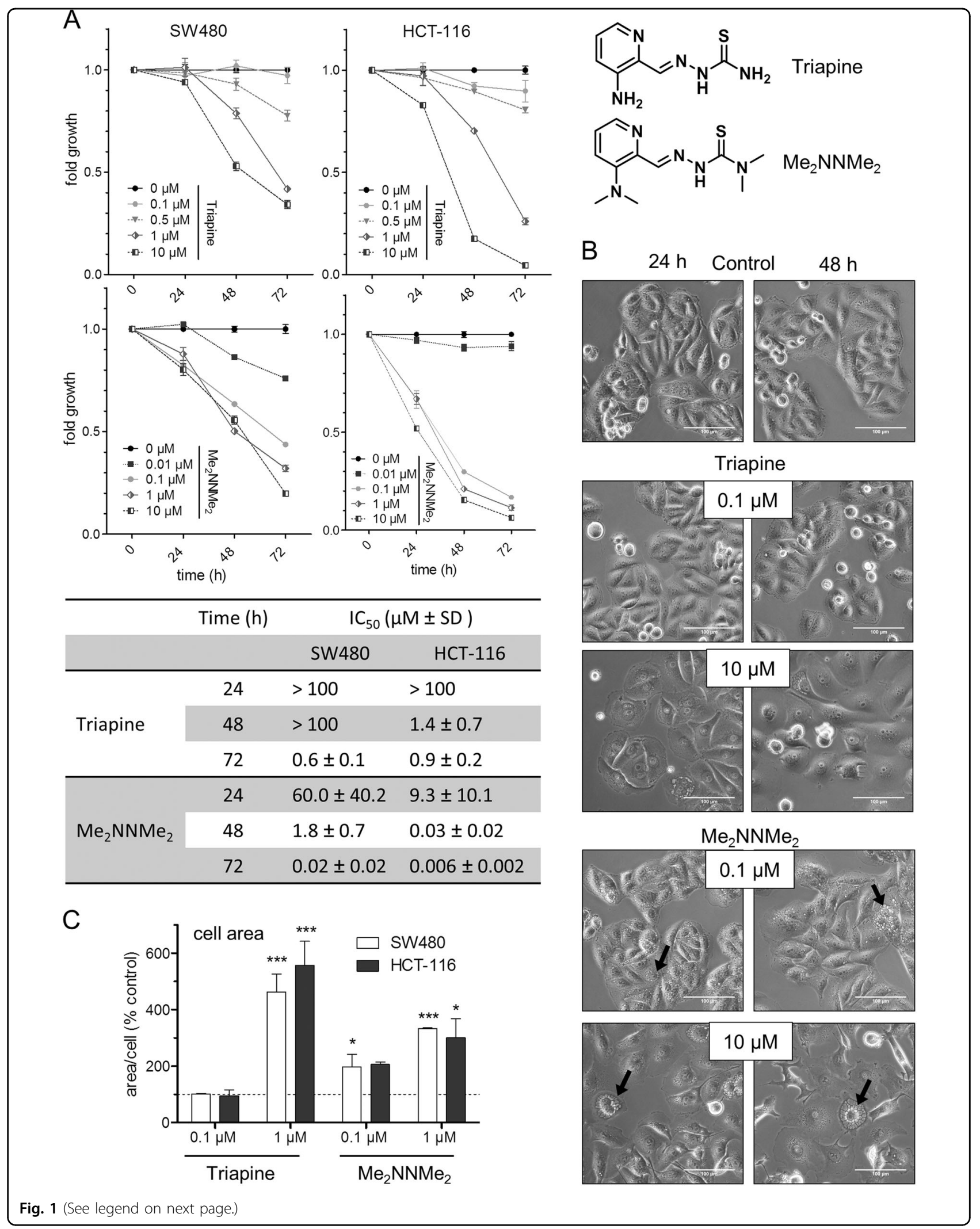


(see figure on previous page)

Fig. 1 Activity of Triapine and its derivative $\mathbf{M e}_{2} \mathrm{NNMe}_{2}$. a Time-dependent cell viability of SW480 and HCT-116 cells treated with either Triapine or $\mathrm{Me}_{2} \mathrm{NNMe}_{2}$, determined by MTT assay after 24, 48, and $72 \mathrm{~h}$. Values given in the graph are the mean \pm standard deviation of triplicates from one representative experiment out of three, normalized to the untreated control of the same time-point. IC $C_{50}$ values $(\mu \mathrm{M}) \pm$ standard deviations (SD) are given in the table. $\mathbf{b}$ Morphological changes in SW480 cells induced by 24 and $48 \mathrm{~h}$ treatment with the indicated concentrations of Triapine or $\mathrm{Me}_{2} \mathrm{NNMe}_{2}$. Cytoplasmic vacuoles were mainly seen with $\mathrm{Me}_{2} \mathrm{NNMe}_{2}$ (arrows). Scale bar: $100 \mu \mathrm{m}$. c Increase in cell size of SW480 and HCT-116 cells treated with the indicated concentrations of Triapine and $\mathrm{Me}_{2} \mathrm{NNMe}_{2}$ for $48 \mathrm{~h}$

action from Triapine ${ }^{2,12,13}$. In particular, their interaction with intracellular copper ions might be important, as intracellularly formed copper complexes have been suggested to be the active metabolites of nanomolar TSCs ${ }^{12-14}$. In this regard, during our recent studies, we have discovered that treatment with $\mathrm{Me}_{2} \mathrm{NNMe}_{2}$ as well as $\mathrm{Dp} 44 \mathrm{mT}$ resulted in the formation of perinuclear cytoplasmic vesicles ${ }^{11}$ that are characteristic for paraptosis, a recently described new type of programmed cell death ${ }^{15,16}$. Further hallmarks of paraptosis include mitochondrial swelling and damage, caspase-independent cell death and the absence of membrane blebbing/DNA condensation or fragmentation. Moreover, disruption of endoplasmic reticulum (ER) homeostasis, activation of MAPK signaling as well as protection by the thiolcontaining radical scavenger $N$-acetylcysteine (NAC) and the MEK inhibitor U0126 have been reported ${ }^{15,16}$. However, the exact molecular mechanisms underlying paraptosis induction are widely unexplored.

So far, mainly diverse natural compounds have been identified as paraptosis inducers. Interestingly, the list also includes some copper complexes ${ }^{17-19}$, supporting the idea that nanomolar TSCs could also induce this novel form of cell death. Therefore, in this study, we investigated the role of apoptotic and paraptotic cell death in the mode of action of Triapine and $\mathrm{Me}_{2} \mathrm{NNMe}_{2}$. Our experiments revealed that treatment with $\mathrm{Me}_{2} \mathrm{NNMe}_{2}$ induces all of the main hallmarks of paraptotic cell death. In addition, we identified the inhibition of the ER-resident protein disulfide isomerase (PDI) as a potential target of the intracellularly formed $\mathrm{Me}_{2} \mathrm{NNMe}_{2}$ copper metabolite.

\section{Results}

\section{Anticancer activity of Triapine and $\mathrm{Me}_{2} \mathrm{NNMe}_{2}$}

Cytotoxicity and morphological changes induced by Triapine and $\mathrm{Me}_{2} \mathrm{NNMe}_{2}$ were investigated in SW480 and HCT-116 cells at different time points (Fig. 1a). In general, HCT-116 cells proved to be more sensitive to TSC treatment than SW480. Moreover, in accordance with previous results ${ }^{11}$, double-dimethylation of Triapine resulted in markedly higher activity in a time-dependent manner. The two drugs had distinct effects on cell morphology, as shown in Fig. 1b, c. Especially, Triapinetreated cells were characterized by increased cell area (up to $500 \%$ ) and flattening (Fig. 1c). In contrast, treatment with $\mathrm{Me}_{2} \mathrm{NNMe}_{2}$ led to formation of cytoplasmic vesicles (see black arrows in Fig. 1b), which dose- and timedependently increased in size and number (Fig. 1b, Suppl. Figure 1). These observations were consistent in both cell lines. Comparable vesicle formation was also observed with the other nanomolar TSCs, DpC, Dp44mT, and Coti-2 (Suppl. Figure 2).

\section{$\mathrm{Me}_{2} \mathrm{NNMe}_{2}$ accumulation in the ER-derived vesicles}

Several groups have reported that paraptosis induction is associated with the appearance of cytoplasmic vesicles originating from the $\mathrm{ER}^{15,16}$. To investigate whether the cytoplasmic vesicles seen in $\mathrm{Me}_{2} \mathrm{NNMe}_{2}$-treated cells also arise from the ER, transfection experiments with ERlocalized YFP were performed (Fig. 2a). As visualized by live-cell microscopy, ER-derived vesicles formed around the nucleus and rapidly increased in size (by fusion) (Fig. 2b). Moreover, no overlap of these vesicles with mitochondria or lysosomes was found (Fig. 2c and Suppl. Figure 3). Consequently, we concluded that the observed cytoplasmic vesicles after $\mathrm{Me}_{2} \mathrm{NNMe}_{2}$ treatment originated solely from the ER.

Mapping cells by Raman microspectroscopy and subsequent principal component analysis (PCA) revealed a unique biochemical composition of these vesicles compared to the rest of the cell (Fig. 2d). Component spectra suggested enrichment of lipids (bands at $\sim 1295 \mathrm{~cm}^{-1}$, $1435-1480 \mathrm{~cm}^{-1}$, and $\sim 1650 \mathrm{~cm}^{-1}$ ) in these vesicles, while bands corresponding to nucleic acids $\left(\sim 715 \mathrm{~cm}^{-1}\right.$, $\sim 775 \mathrm{~cm}^{-1}, \sim 1090 \mathrm{~cm}^{-1}$, and $\sim 1570 \mathrm{~cm}^{-1}$ ) were weaker compared to the rest of the cell (Suppl. Figure $4 \mathrm{~A})^{20}$. Furthermore, classical least squares (CLS) fitting of the spectrum of the pure substance (Suppl. Figure 4B) to the Raman map revealed that $\mathrm{Me}_{2} \mathrm{NNMe}_{2}$ appears to accumulate in these vesicles (Fig. 2d), indicating that the compound might have its intracellular target in the ER.

\section{Impact of the TSCs on mitochondrial integrity}

Paraptotic cell death is frequently associated with changes of mitochondrial morphology and functionality ${ }^{21-27}$. Consequently, JC-1 staining was conducted to evaluate the impact of both drugs on mitochondrial membrane potential. Upon treatment with Triapine, only slight, non-significant effects were detected in both cell lines (Fig. 3a), while $\mathrm{Me}_{2} \mathrm{NNMe}_{2}$ had a profound impact. In detail, in SW480 cells, at all investigated concentrations $\sim 10 \%$ of the cells displayed depolarized mitochondria. In 


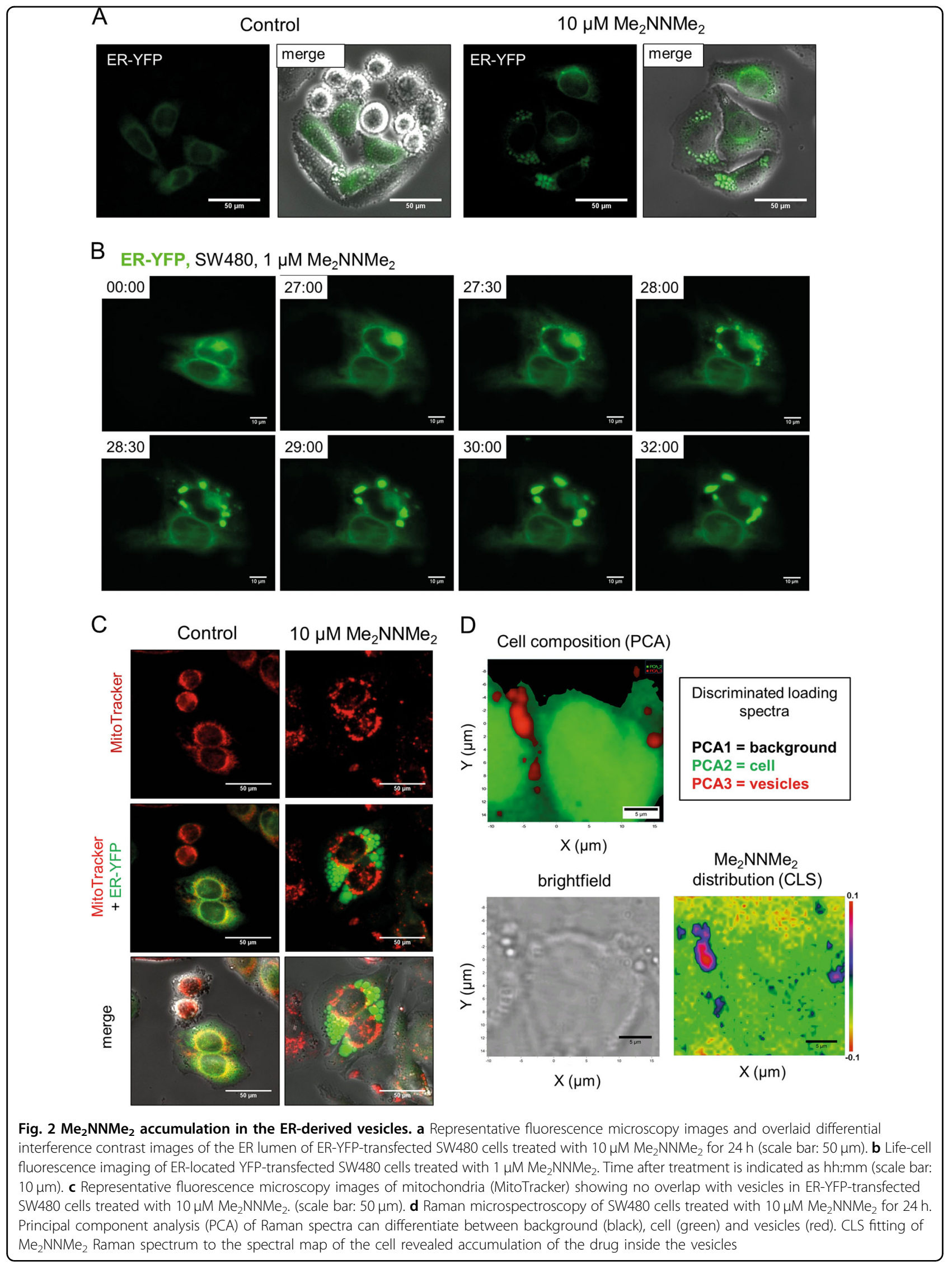



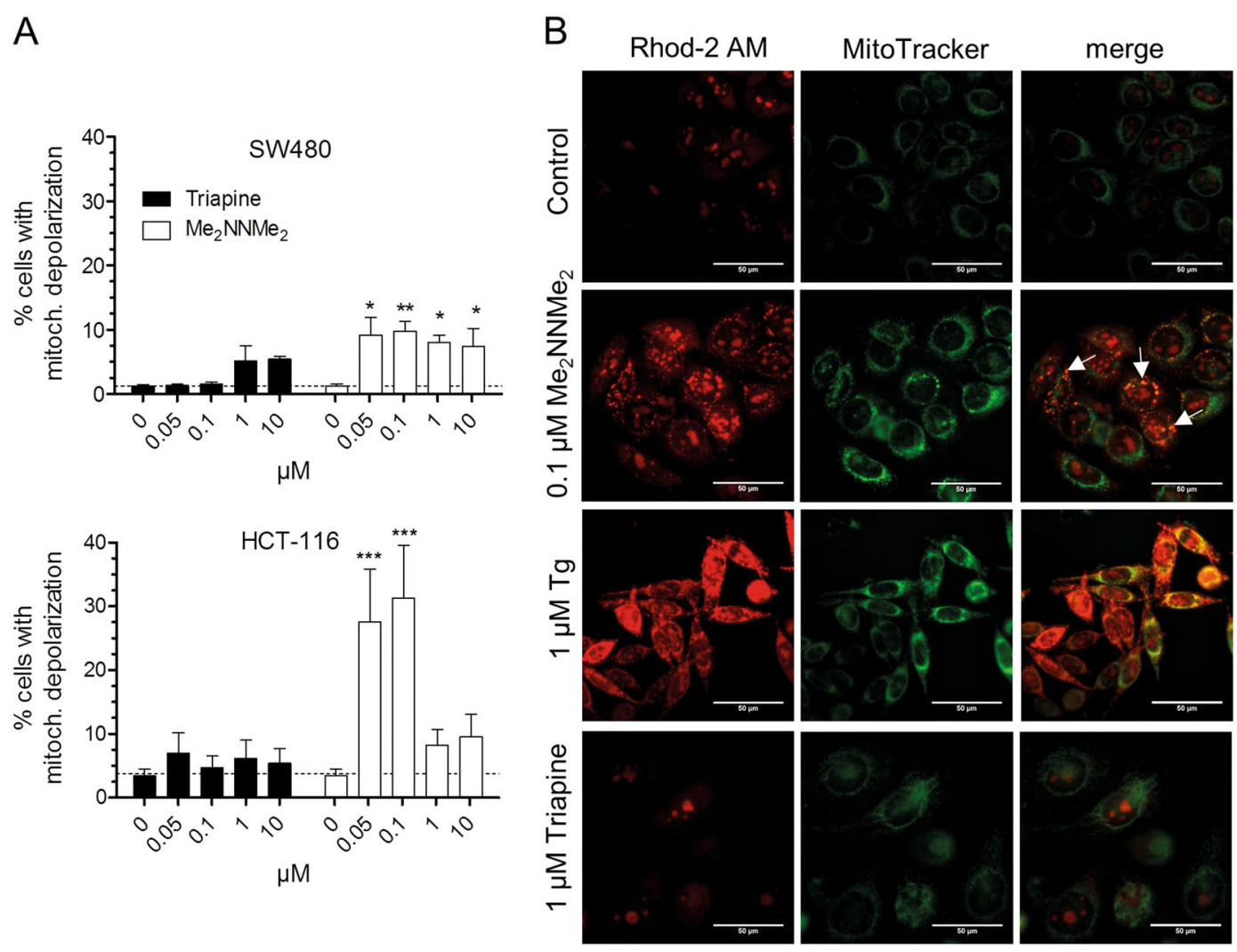

C

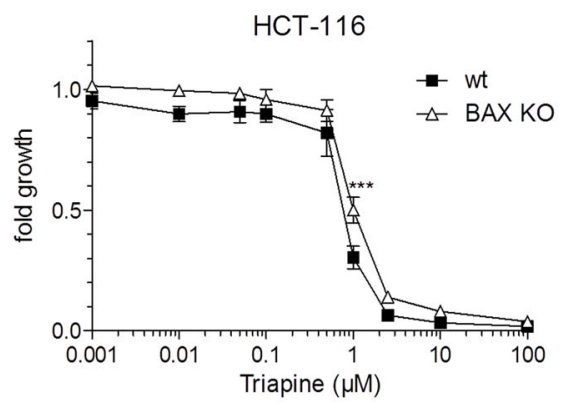

D

Triapine $(\mu \mathrm{M}) \mathrm{Me}_{2} \mathrm{NNMe}_{2}(\mu \mathrm{M})$

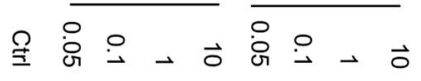
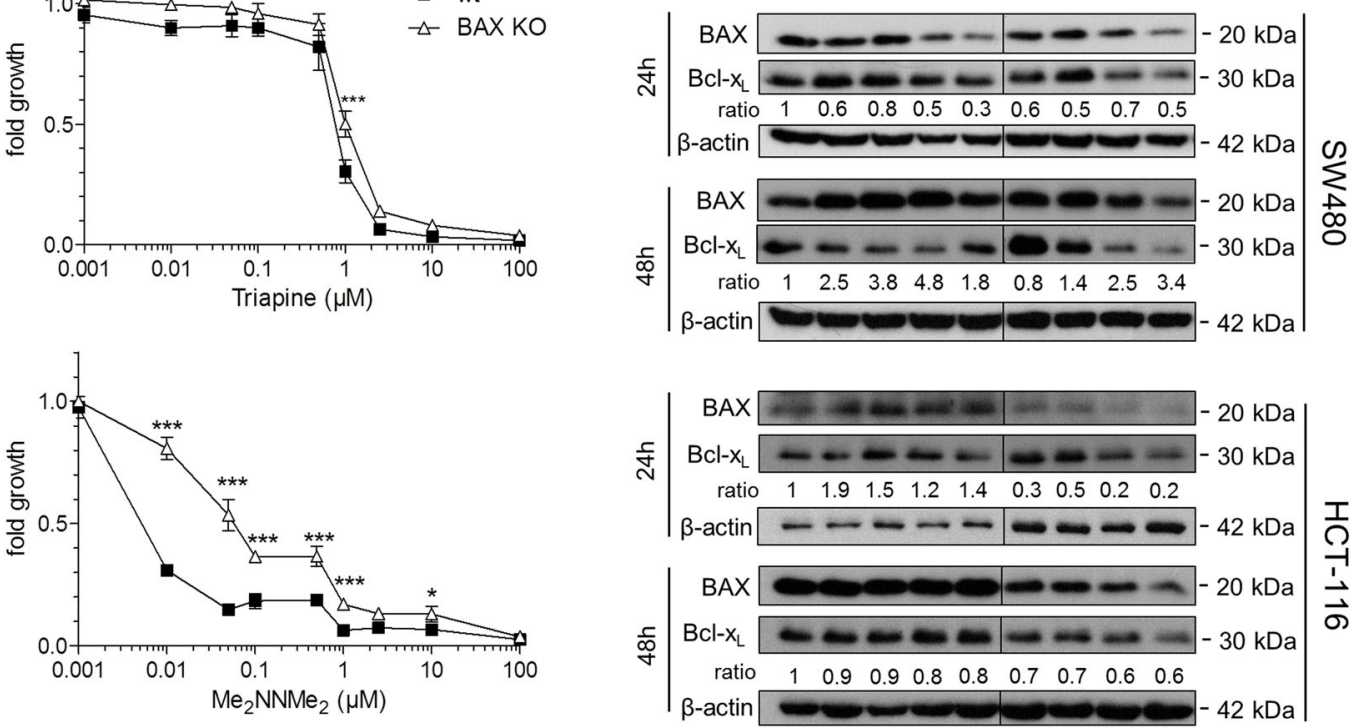

Fig. 3 (See legend on next page.) 
(see figure on previous page)

Fig. 3 Mitochondrial involvement in the activity of Triapine and $\mathrm{Me}_{2} \mathrm{NNMe}_{2}$. a Mitochondrial membrane potential depolarization measured by the percentage of cells with decreased JC-1 fluorescence (red). SW480 or HCT-116 cells were treated with the indicated concentrations of Triapine or $\mathrm{Me}_{2} \mathrm{NNMe}_{2}$ for $24 \mathrm{~h}$. Values given are the mean \pm standard deviation of three independent experiments. b Fluorescence microscopy of increased calcium levels (Rhod-2 $\mathrm{AM}$ in red) specifically in the mitochondria (MitoTracker in green) after thapsigargin $(\mathrm{Tg}, 1 \mu \mathrm{M}), \mathrm{Me}_{2} \mathrm{NNMe}_{2}(0.1 \mu \mathrm{M})$ or Triapine $(1 \mu \mathrm{M})$ treatment of SW480 cells for $48 \mathrm{~h}$ (scale bar: $50 \mu \mathrm{m}$ ). White arrows indicate co-localization. c Cell viability of HCT-116 wild-type (wt) and BAX knockout (KO) cells measured by MTT after $72 \mathrm{~h}$ treatment with indicated concentrations of Triapine or $\mathrm{Me}_{2} \mathrm{NNMe}_{2}$. Values given are the mean \pm standard deviation of triplicates of one representative experiment out of three. $\mathbf{d}$ Western blot analysis of BAX and BCl-X expressed by SW480 and HCT-116 cells treated with Triapine or Me $\mathrm{NNMe}_{2}$ for 24 or $48 \mathrm{~h}$. The ratio of BAX to BCl- $x_{L}$ is given below the respective bands. $\beta$-actin was used as a loading control. Significance was calculated to control with one-way (a) and to wt cells with two-way (c) ANOVA and Bonferroni's multiple comparison test $\left({ }^{* * *} p<0.001,{ }^{* *} p \leq 0.01,{ }^{*} p \leq 0.05\right.$ )

contrast, $30 \%$ of HCT-116 cells showed mitochondrial depolarization at 0.05 and $0.1 \mu \mathrm{M} \mathrm{Me} \mathrm{NNMe}_{2}$, which decreased to about $10 \%$ at higher concentrations. In parallel to mitochondrial depolarization, $\mathrm{Me}_{2} \mathrm{NNMe}_{2}$, but not Triapine, induced mitochondrial fragmentation or swelling (a main hallmark of paraptosis) already at $0.1 \mu \mathrm{M}$ (Suppl. Figure 5). In order to investigate whether this observed swelling is accompanied by increased intramitochondrial $\mathrm{Ca}^{2+}$ levels, Rhod-2 AM stains were performed. Indeed, distinct accumulation of mitochondrial $\mathrm{Ca}^{2+}$ together with organelle swelling was observed in $\mathrm{Me}_{2} \mathrm{NNMe}_{2}$-exposed cells (Fig. 3b). In contrast, thapsigargin, a well-known SERCA (ER-localized $\mathrm{Ca}^{2+}$ ATPase) inhibitor and ER stress inducer, initiated mitochondrial $\mathrm{Ca}^{2+}$ accumulation but no organelle swelling. Together with the lack of organelle swelling, Triapine had also no impact on mitochondrial $\mathrm{Ca}^{2+}$ levels (Fig. 3b).

In agreement with the suggested contribution of mitochondria to $\mathrm{Me}_{2} \mathrm{NNMe}_{2}$ activity, HCT-116 cells with a BAX knockout ${ }^{18}$ were (in contrast to Triapine) significantly less sensitive to the methylated derivative (Fig. 3c). Interestingly, $\mathrm{Me}_{2} \mathrm{NNMe}_{2}$ activity was accompanied by a decrease of both pro-apoptotic BAX as well as anti-apoptotic $\mathrm{Bcl}-\mathrm{x}_{\mathrm{L}}$ protein levels in $\mathrm{BAX}$ wild-type cells, which argues against induction of apoptosis via the intrinsic (mitochondrial) pathway (Fig. 3d). Taken together, this indicates that $\mathrm{Me}_{2} \mathrm{NNMe}_{2}$ distinctly impacts on mitochondrial integrity already at very low drug concentrations and disruption of mitochondrial $\mathrm{Ca}^{2+}$ homeostasis is a key event in $\mathrm{Me}_{2} \mathrm{NNMe}_{2}$-induced paraptosis.

\section{Caspase independence of $\mathrm{Me}_{2} \mathrm{NNMe}_{2}$ anticancer activity}

As paraptosis is often described as a caspase-independent process ${ }^{15,16}$, as a next step the impact of the pancaspase inhibitor $\mathrm{z}-\mathrm{VAD}-\mathrm{FMK}$ on the activity of the two TSCs was investigated. As shown in Fig. 4a, there was no relevant effect of $\mathrm{z}$-VAD-FMK on the anticancer activity of the tested TSCs, in contrast to TRAIL, which was used as a positive control (Suppl. Figure 6). In addition, treatment with the pan-caspase inhibitor did not prevent the formation of cytoplasmic vesicles induced by $\mathrm{Me}_{2} \mathrm{NNMe}_{2}$ (Fig. 4b). To confirm the caspase independence of $\mathrm{Me}_{2} \mathrm{NNMe}_{2}$-induced cell death, annexin V (AV) stains were performed in the presence and absence of the pancaspase inhibitor (Fig. 4c). Caspase inhibition had no significant impact (calculated to control by one-way ANOVA and Bonferroni's multiple comparison test) on the $\mathrm{AV}^{+}$cell fractions after $\mathrm{Me}_{2} \mathrm{NNMe}_{2}$ treatment in both cell lines. In contrast, Triapine-induced cell death in HCT-116 was strongly diminished upon addition of $\mathrm{z}$ VAD-FMK, suggesting cell line-dependent apoptosis induction by this compound.

\section{The role of MAPKs in $\mathrm{Me}_{2} \mathrm{NNMe}_{2}$-induced paraptosis}

There are indications that MAPK signaling plays an important role in the execution of paraptotic cell death ${ }^{16,28}$. However, whether and how $\mathrm{Me}_{2} \mathrm{NNMe}_{2}$ activity impacts on this pathway is so far unknown. Consequently, as a first step, we compared gene signatures of whole-genome gene expression arrays performed with $0.1 \mu \mathrm{M}$ and $1 \mu \mathrm{M} \mathrm{Me} \mathrm{NNMe}_{2}$ treatment or untreated cells. Gene set enrichment analysis (GSEA) of these data showed significant upregulation of MAPK signaling pathway genes in treated as compared to untreated cells at both concentrations (Fig. 5a). A more detailed illustration of the genes up- (red) or down- (blue) regulated in this KEGG pathway is shown in Fig. 5b. When comparing these mRNA data with Western blot analysis of MEK and ERK, interestingly, both Triapine and $\mathrm{Me}_{2} \mathrm{NNMe}_{2}$ treatment had a tendency to stimulate the MAPK signaling at higher drug concentrations (Fig. 5c). However, at lower doses strongly reduced phosphorylation (especially of MEK1/2) was observed, indicating that stimulation of the MAPK pathway could be due to a compensatory feedback loop.

To gain more insight into the role of the MAPK pathway in the activity of our TSCs, several MEK inhibitors (U0126, PD98058, trametinib, and selumetinib) with different affinities for MEK1 and MEK2 were used. As seen in Fig. 6a and Suppl. Table 1, all inhibitors were able to protect cells against $\mathrm{Me}_{2} \mathrm{NNMe}_{2}$-induced cytotoxicity. However, only U0126 distinctly reduced vesicle formation in $\mathrm{Me}_{2} \mathrm{NNMe}_{2}$ (Fig. 6b, c). The effects of U0126 were also confirmed in HCT-116 cells (data not shown). In contrast to $\mathrm{Me}_{2} \mathrm{NNMe}_{2}$, Triapine activity was largely unaffected by the MEK inhibitors. As U0126 is the only inhibitor that 
A

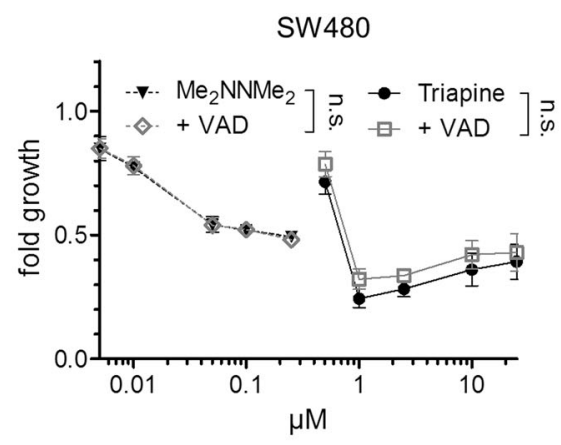

$\mathrm{B}$
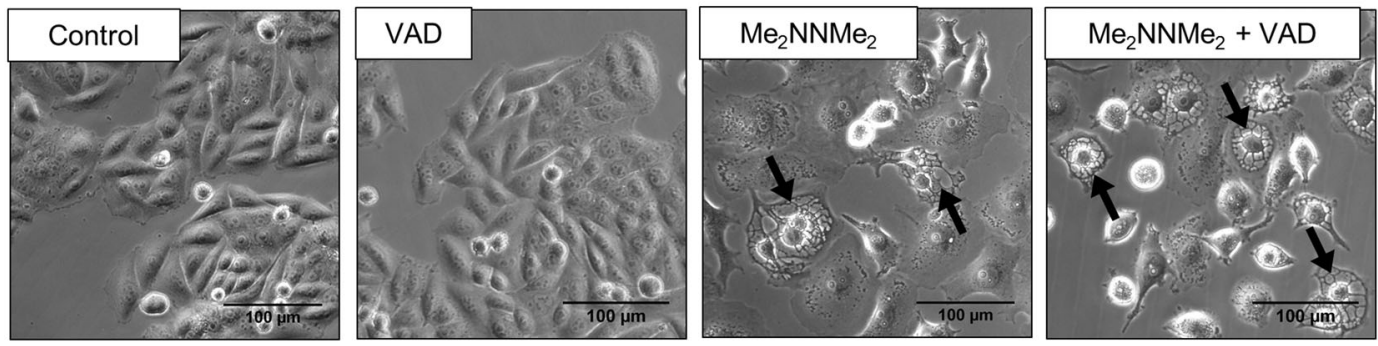

C
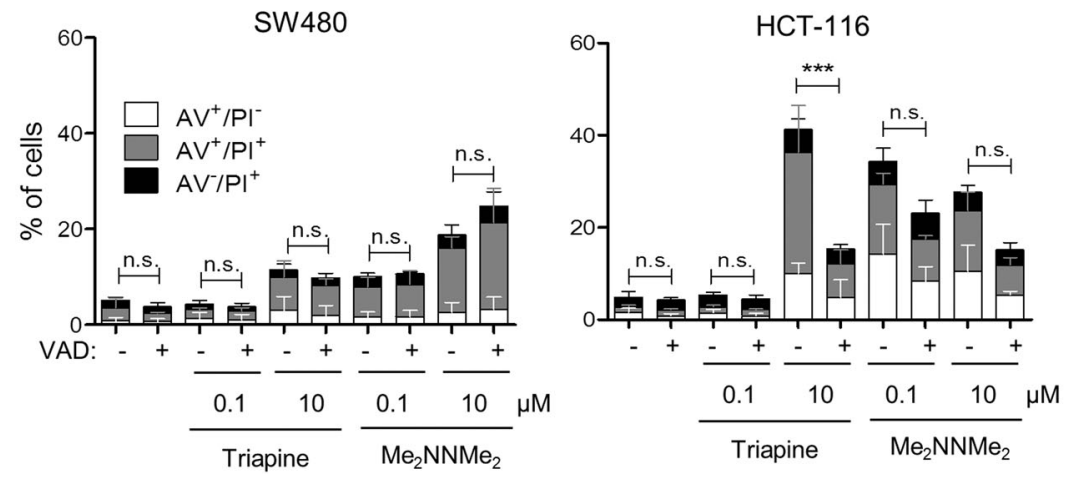

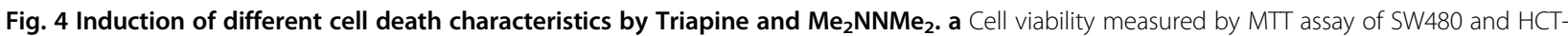
116 cells after $72 \mathrm{~h}$ treatment with the indicated concentrations of Triapine (full lines) or $\mathrm{Me}_{2} \mathrm{NNMe}_{2}$ (dotted lines) alone or in combination with 10 $\mu \mathrm{M}$ z-VAD-FMK (VAD, gray lines). Values given are the mean \pm standard deviation of triplicates from one representative experiment out of three. b Phase-contrast microscopy images of SW480 cells treated with $10 \mu \mathrm{M} \mathrm{Me} \mathrm{NNMe}_{2}$ or $25 \mu \mathrm{M}$ z-VAD-FMK as well as the combination (scale bar: 100 $\mu \mathrm{m})$. c Percentage of annexin V-positive $\left(\mathrm{AV}^{+}\right)$and/or PI ${ }^{+}$SW480 or HCT-116 cells detected by flow cytometry after $48 \mathrm{~h}$ of Triapine or Me $\mathrm{NNMe}_{2}$ treatment in combination with $10 \mu \mathrm{M} z-V A D-F M K(V A D)$. Values given are the mean \pm standard deviation of three independent experiments. For calculation of significance $\mathrm{AV}^{+}$cell fractions $\left(\mathrm{AV}^{+} / \mathrm{PI}^{-}, \mathrm{AV}^{+} / \mathrm{PI}^{+}\right)$were added. Significance to control was calculated by two-way $(\mathbf{a})$ or one-way $(\mathbf{c})$ ANOVA and Bonferroni's multiple comparison test using GraphPad Prism software $\left({ }^{* * *} p<0.001,{ }^{* *} p \leq 0.01,{ }^{*} p \leq 0.05\right)$

inhibits MEK1 and 2 to a similar extent (while the others have a stronger preference for MEK1), we hypothesized that MEK2 could have a special role in $\mathrm{Me}_{2} \mathrm{NNMe}_{2}$ activity. To further evaluate this hypothesis, knockdown experiments using siRNA against MEK2 were performed (Fig. 6d). Indeed, further analysis revealed that $\mathrm{Me}_{2} \mathrm{NNMe}_{2}$-induced vacuolization decreased upon MEK2 knockdown (Fig. 6e, f) confirming the importance of this protein in the formation of paraptotic vesicles by $\mathrm{Me}_{2} \mathrm{NNMe}_{2}$. Noteworthy, also induction of vesicles and anticancer activity of other nanomolar TSC (DpC, Dp44mT, and Coti-2) could be inhibited by U0126 (Suppl. Figure 7), indicating induction of paraptotic cell death also with these TSCs.

\section{$\mathrm{Me}_{2} \mathrm{NNMe}_{2}$-induced ER stress based on disturbed ER thiol redox homeostasis}

So far, there are only a few hypotheses on the exact mechanisms underlying paraptosis induction. In case of natural products, especially proteasome inhibition 


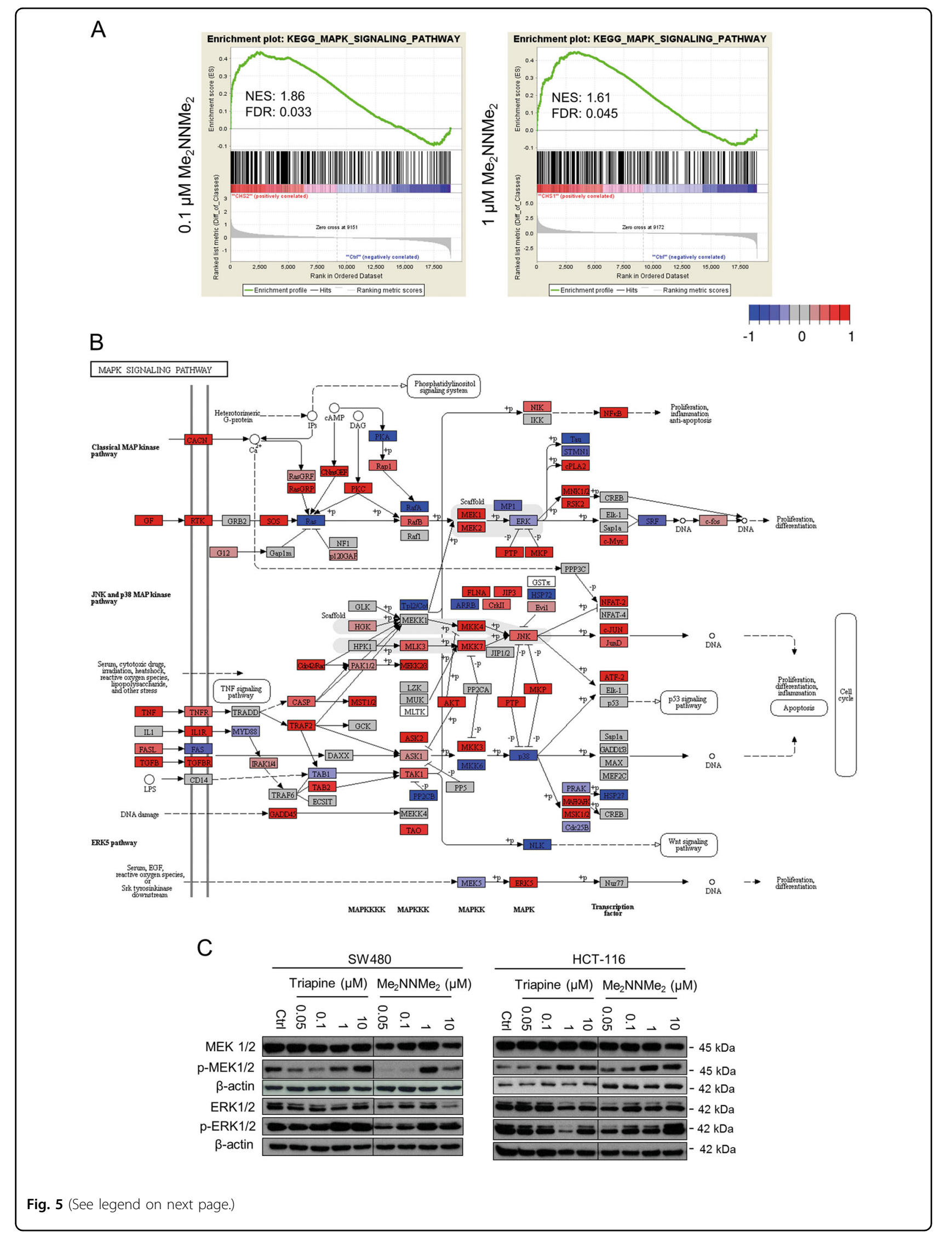


(see figure on previous page)

Fig. 5 Role of the MAPK pathway in the activity of Triapine and $\mathbf{M e}_{2} \mathbf{N N M e}_{2}$. a GSEA from whole-genome gene expression data revealed significant enrichment of genes in the "MAPK signaling pathway" gene set in SW480 cells treated with 0.1 or $1 \mu \mathrm{M} \mathrm{Me} \mathrm{NNMe}_{2}$ compared to untreated cells. Normalized enrichment score (NES) and false discovery rate (FDR) are given. b lllustration of genes up- (red) or down-regulated (blue) in the KEGG-derived "MAPK signaling pathway" of $\mathrm{Me}_{2} \mathrm{NNMe}_{2}(1 \mu \mathrm{M})$-treated compared to untreated SW480 cells using whole-genome gene expression data. $\mathbf{c}$ Western blot analysis of MEK1/2 and ERK1/2 as well as their phosphorylated protein levels in SW480 and HCT-116 cells treated with indicated concentrations of Triapine and $\mathrm{Me}_{2} \mathrm{NNMe}_{2}$ for $24 \mathrm{~h}$. $\beta$-actin was used as a loading control

resulting in (unfolded) protein stress has been suggested $^{16,29}$. Consequently, paraptosis induction by such drugs is often dependent on active protein synthesis. However, inhibition of protein synthesis (by cycloheximide) had no impact on the activity of $\mathrm{Me}_{2} \mathrm{NNMe}_{2}$ and no difference was observed in the impact on protein ubiquitination levels between Triapine and $\mathrm{Me}_{2} \mathrm{NNMe}_{2}$ (data not shown), suggesting another mode of action. Based on ER localization of $\mathrm{Me}_{2} \mathrm{NNMe}_{2}$ in the Raman microscopy studies together with the profound ER blebbing, we hypothesized that $\mathrm{Me}_{2} \mathrm{NNMe}_{2}$ might have a target in this organelle. In line with this hypothesis, subsequent experiments confirmed a specific form of ER stress especially in $\mathrm{Me}_{2} \mathrm{NNMe}_{2}$-treated cells. In more detail, $\mathrm{Me}_{2} \mathrm{NNMe}_{2}$ (but not Triapine) treatment resulted in enhanced nuclear localization of CHOP, an ER stressinduced transcription factor, (Fig. 7a and Suppl Figure 8) together with increased phosphorylation of its upstream activator PERK (Fig. 7b). In contrast, no changes in other ER stress markers, such as BiP, IRE1 $\alpha$, calnexin, or changes in the phosphorylation of eIF2- $\alpha$ were detected. Remarkably, in contrast to thapsigargin, CHOP-regulated ero1L- $\alpha$ (an ER-specific thiol oxidase) as well as the ERlocalized chaperone, isomerase and thiol oxidoreductase PDI were upregulated by both Triapine and $\mathrm{Me}_{2} \mathrm{NNMe}_{2}$ (Fig. 7b). Moreover, our array data showed that the expression of these proteins was also increased on mRNA level upon $\mathrm{Me}_{2} \mathrm{NNMe}_{2}$ treatment (Fig. 7c), indicating increased gene transcription of these CHOP-target genes.

Interestingly, there are reports that PDI is able to bind and reduce copper (although the impact of copper binding on the enzymatic activity is not fully characterized $)^{30}$. As $\mathrm{Me}_{2} \mathrm{NNMe}_{2}$ has strong copper-binding properties and our previous studies already indicated that addition of copper strongly increases the activity of $\mathrm{Me}_{2} \mathrm{NNMe}_{2}{ }^{11}$, we hypothesized that our drug or its copper metabolite interferes with the functionality of PDI. Subsequently performed enzyme inhibition assays revealed that, indeed, the copper complex of $\mathrm{Me}_{2} \mathrm{NNMe}_{2}$ (but not of Triapine) had strong PDI-inhibitory potential (Fig. 7d). Noteworthy, the metal-free drugs did not inhibit the enzyme, even at high concentrations, suggesting that prior (intracellular) copper chelation is necessary for PDI inhibition. Similar activity was also detected with the copper complexes of $\mathrm{DpC}$ and Dp44mT (Suppl. Figure 9).
PDI plays a key role in the ER thiol redox homeostasis by forming and rearranging disulfide bonds during protein folding. In this process, PDI oxidizes unfolded target proteins with the help of oxidized thiol-containing molecules, such as GSSG or ero1L- $\alpha$, thereby resulting in the reduction of these molecules ${ }^{31}$. To gain more insight into the role of the ER thiol redox homeostasis in the mode of action of $\mathrm{Me}_{2} \mathrm{NNMe}_{2}$, co-incubation experiments with the thiol-containing antioxidants NAC and 1-thioglycerol were performed. Indeed, both compounds protected the cells from $\mathrm{Me}_{2} \mathrm{NNMe}_{2}$ (but not Triapine)-induced cytotoxicity (Fig. 7e and Suppl. Figure 10). In addition, NAC also reduced anticancer activity induced by DpC, Dp44mT and Coti-2 (Suppl. Figure 7C). Noteworthy, these $\mathrm{Me}_{2} \mathrm{NNMe}_{2}$-induced effects were not based on enhanced global superoxide (Fig. 7f) or $\operatorname{ROS}^{11}$ levels but coincided with increased glutathione and especially GSSG levels (Fig. 7g). This suggests that nanomolar TSCs induce either a very local, organelle specific form of ROS or ROS generation does not play a major role in their anticancer activity.

Taken together, these results indicate that $\mathrm{Me}_{2} \mathrm{NNMe}_{2}$ might form an intracellular copper metabolite with PDIinhibitory properties, which then results in disturbed ER thiol redox balance and paraptosis induction. The proposed mode of action is shown in Fig. 8.

\section{Discussion}

In anticancer therapy, resistance of cancer cells to apoptosis is a major obstacle to successful treatment and the cause of many cancer-associated deaths ${ }^{32}$. Targeting cancer cells by the induction of paraptosis, a recently discovered alternative caspase-independent cell death pathway ${ }^{15,16}$, offers the opportunity to overcome apoptosis resistance. However, the mechanisms of paraptosis are still not fully understood (and sometimes even contradictory observations have been published ${ }^{16,33}$ ), making the in-depth investigation of the underlying signaling pathways of high importance. In general, there are several main hallmarks of paraptosis that are widely accepted. Among these, cytoplasmic (ER-derived) vacuolization, mitochondrial swelling/damage, caspase independence together with absence of membrane blebbing as well as DNA condensation/fragmentation, disruption of ER homeostasis, activation of MAPK signaling, protection by 
A

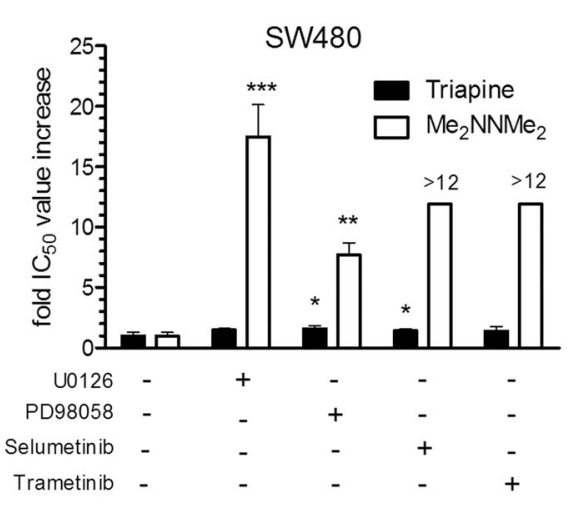

C

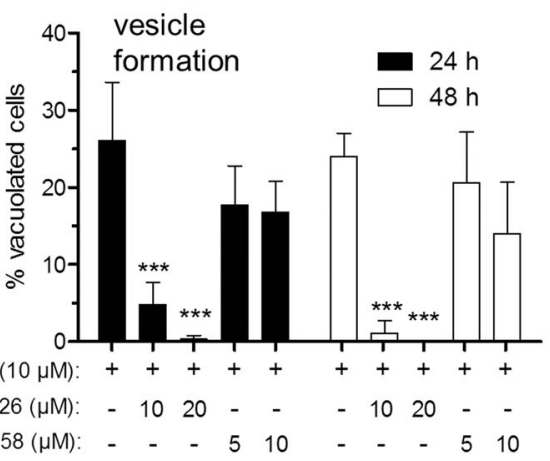

D

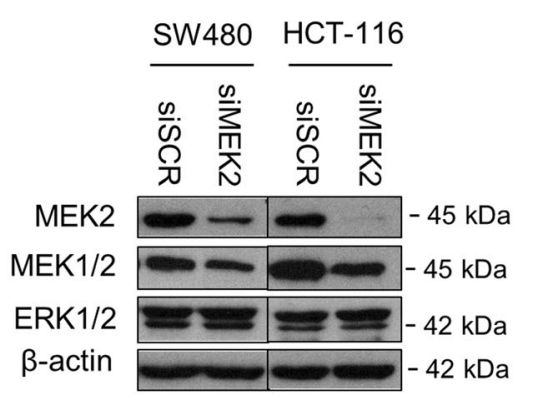

F

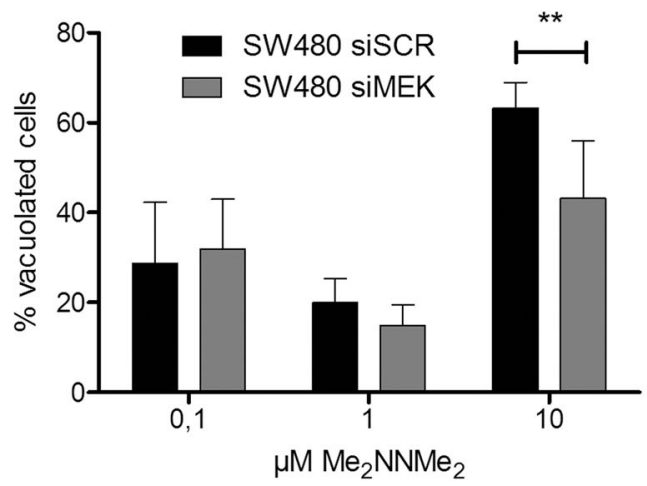

B
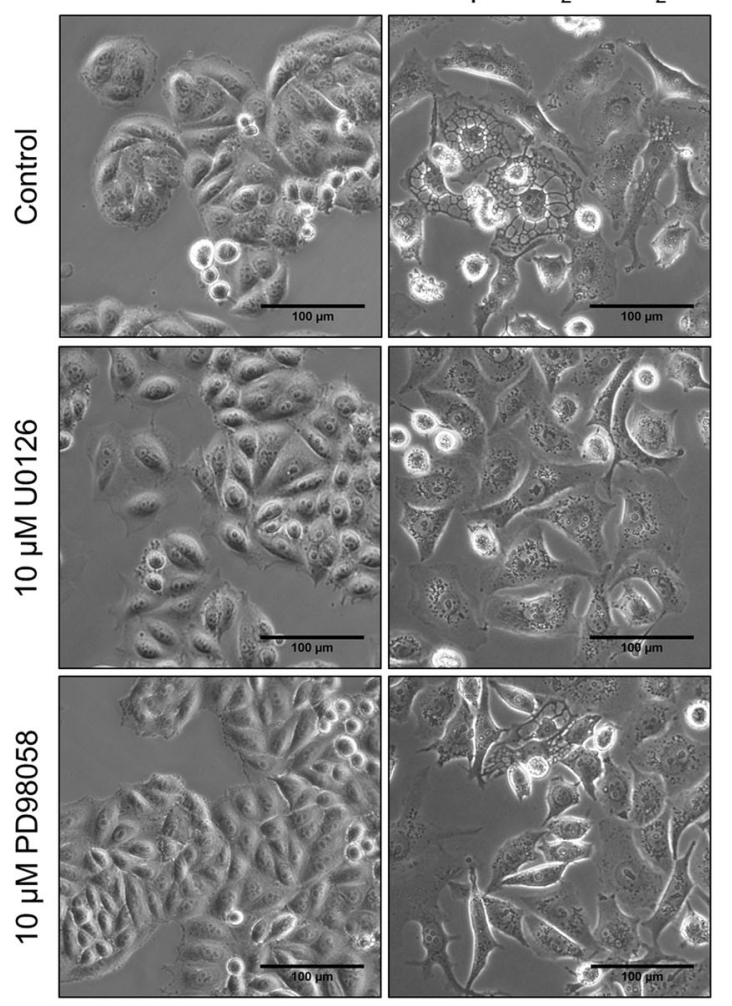

$\mathrm{E}$

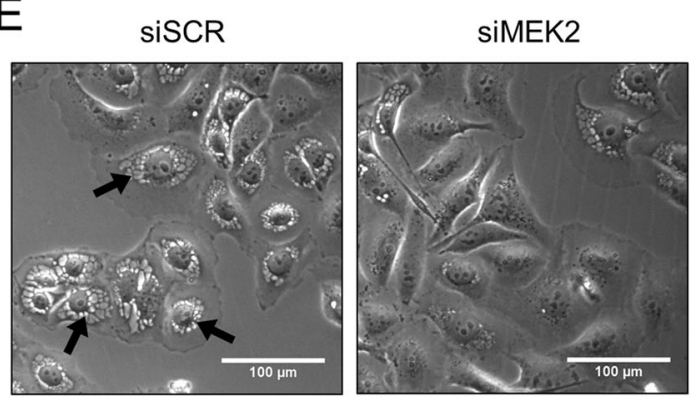

SW480, 24 h, $10 \mu \mathrm{M} \mathrm{Me}_{2} \mathrm{NNMe}_{2}$

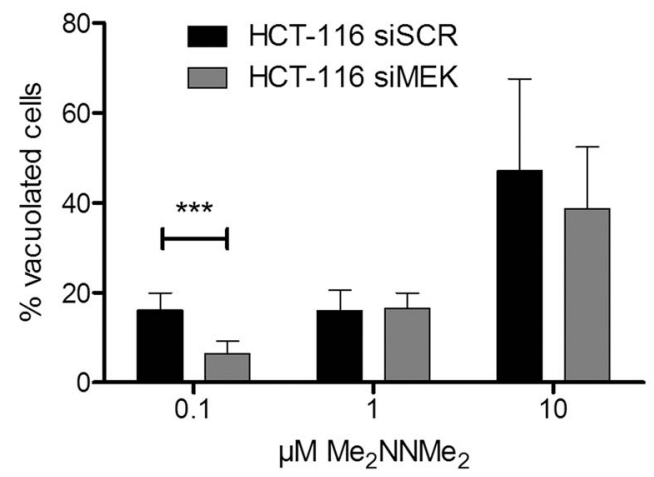

Fig. 6 (See legend on next page.) 
(see figure on previous page)

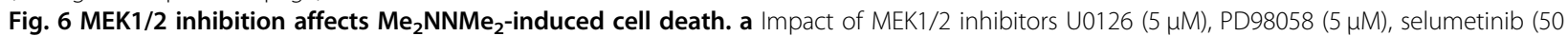
$\mathrm{nM})$ or trametinib $(100 \mathrm{nM})$ on viability of Triapine- or $\mathrm{Me}_{2} \mathrm{NNMe}_{2}$-treated SW480. Change in viability is given as mean fold $I_{50}$ value increase \pm standard deviation compared to Triapine or $\mathrm{Me}_{2} \mathrm{NNMe}_{2}$ treatment alone, measured by three independent MTT viability experiments. $\mathbf{b}$ Representative phase-contrast microscopy images of SW480 cells treated with $\mathrm{Me}_{2} \mathrm{NNMe}_{2}(10 \mu \mathrm{M})$ and $\mathrm{U} 0126(20 \mu \mathrm{M})$ or PD98058 (10 $\left.\mu \mathrm{M}\right)$ as well as the combinations for $48 \mathrm{~h}$ (scale bar: $100 \mu \mathrm{m}$ ). c Percentage of vacuolated cells counted from phase-contrast microscopy images seen in $\mathbf{b}$. Values given are the mean \pm standard deviation of three images with at least 30 cells in total. Significance to single treatment was calculated by one-way ANOVA and Bonferroni's multiple comparison test $\left({ }^{* * *} p<0.001,{ }^{* *} 0.001 \geq p \leq 0.01,{ }^{*} 0.01 \geq p \leq 0.05\right.$ ). d Protein expression detected by Western blot of MEK2, MEK1/2, and ERK1/2 in SW480 and HCT-116 cells after $48 \mathrm{~h}$ gene silencing with scrambled (siSCR) or MEK2 (siMEK2) siRNA. $\beta$-actin was used as a loading control. e Representative images of SW480 cells transfected with siSCR or siMEK2 and treated with $10 \mu \mathrm{M} \mathrm{Me} \mathrm{NNMe}_{2}$ for $24 \mathrm{~h}$ (scale bar: $100 \mu \mathrm{m}$ ). $\mathbf{f}$ Percentage of cell vacuolization of SW480 or HCT-116 cells transfected with siSCR or siMEK2 and treated with the indicated concentrations of $\mathrm{Me}_{2} \mathrm{NNMe}_{2}$ for $24 \mathrm{~h}$. Values given are the mean \pm standard deviation of several regions of two experiments. Significance to siSCR was calculated by Student's T-test $\left.{ }^{* * *} p<0.001,{ }^{* *} p \leq 0.01\right)$

NAC and U0126 as well as protein synthesis dependence are most prominent ${ }^{15,16}$.

So far, mainly natural compounds, such as celastrol, curcumin or cyclosporine A, were found to induce paraptosis $^{16}$. In addition, a few synthetic drugs, including some copper complexes ${ }^{17,19}$, have been studied. Here, for the first time, we report about paraptosis induction by TSCs. Initiated by the discovery that treatment with nanomolar TSCs, such as $\mathrm{Me}_{2} \mathrm{NNMe}_{2}$ and Dp44mT, resulted in formation of prominent cytoplasmic vesicles ${ }^{11}$, our aim in the here presented study was to investigate whether treatment with $\mathrm{Me}_{2} \mathrm{NNMe}_{2}$ results in paraptosis or a paraptosis-like cell death. Therefore, we have investigated different pathways and organelles involved in (apoptotic) cell death and paraptosis. Through this approach, we found that indeed $\mathrm{Me}_{2} \mathrm{NNMe}_{2}$ induced paraptotic cell death fulfilling several main hallmarks such as swelling of ER and mitochondria, caspase independence and MAPK activation (probably via MEK2 signaling).

Interestingly, Raman microscopy experiments revealed an accumulation of $\mathrm{Me}_{2} \mathrm{NNMe}_{2}$ in the ER-derived vesicles, suggesting that this compound might directly interfere with ER-resident proteins. Subsequent investigations revealed that $\mathrm{Me}_{2} \mathrm{NNMe}_{2}$ treatment indeed induced a specific form of ER stress. In detail, enhanced nuclear localization of CHOP and PERK phosphorylation were detected. Beside these typical ER stress markers, we additionally observed an upregulation of ero1L- $\alpha$ and PDI, which are both involved in the ER thiol redox homeostasis $^{34}$. Here, especially PDI attracted our attention, as it has been recently described as a copper-binding and -reducing protein ${ }^{30}$. This is of relevance as $\mathrm{Me}_{2} \mathrm{NNMe}_{2}$ (and other nanomolar TCSs like DpC and Dp44mT) have been well characterized for their metal-chelating properties and especially formation of an intracellular copper metabolite has been suggested to be crucial for their anticancer activity ${ }^{2,11,12,35,36}$. Thus, the PDI-inhibitory potential of Triapine, $\mathrm{Me}_{2} \mathrm{NNMe}_{2}$ as well as their copper complexes was investigated. Indeed, the copper complexes of $\mathrm{Me}_{2} \mathrm{NNMe}_{2}$ as well as those of $\mathrm{DpC}$ and
Dp44mT were able to potently inhibit the enzyme, while the Triapine copper complex as well as the ligands alone were inactive in this assay. Further evidence connecting TSCs to PDI as a potential target can be seen in the overexpression of the PDI family member $\mathrm{CaBP} 1$ in a L1210 cell subline selected for resistance to 4-methyl-5amino-1-formylisoquinoline TSC (MAIQ) ${ }^{37}$. Although this suggests an important role of this protein class in the mode of action of at least some TSCs, no further studies on this topic have been performed so far. Consequently, the exact evaluation of the mechanisms resulting in the PDI inhibition by some copper TSCs is matter of currently ongoing investigations.

In agreement with the PDI inhibition, subsequent analysis showed that $\mathrm{Me}_{2} \mathrm{NNMe}_{2}$ treatment led to an increase of total glutathione levels, especially of its oxidized form (GSSG) and co-incubation with thiol-containing antioxidants such as NAC or 1-thioglyerol had protective effects. A disrupted thiol redox homeostasis would also explain the enhanced levels of PERK phosphorylation and subsequent $\mathrm{CHOP}$ translocation into the nucleus, as seen upon $\mathrm{Me}_{2} \mathrm{NNMe}_{2}$ treatment ${ }^{38,39}$. CHOP in turn is a transcription factor, which can initiate the observed increased expression of (among others) PDI and ero1L$\alpha^{40-42}$. In general, disruption of the ER thiol redox homeostasis has already been discussed as the cause of ER stress and dilation for other paraptotic inducers ${ }^{16,28,43}$. To the best of our knowledge, this is the first report connecting the induction of paraptosis to the inhibition of ER-resident proteins. Thus, the role of ER enzyme inhibition definitely needs to be addressed in detail in further studies.

With regard to the paraptotic signaling process, the observed thiol-based ER stress is in good agreement with the mitochondrial changes observed after $\mathrm{Me}_{2} \mathrm{NNMe}_{2}$ treatment, as it has already been shown that an altered thiol balance leads to $\mathrm{Ca}^{2+}$ release from the ER and its uptake by the mitochondria ${ }^{44,45}$. Thus, mitochondria are proposed to function as a buffer system by absorbing released $\mathrm{Ca}^{2+46}$. However, prolonged occurrence of 


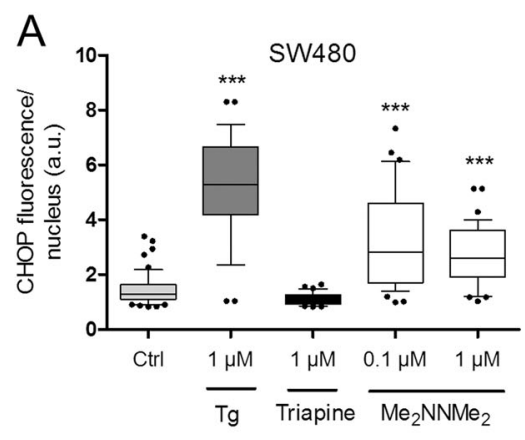

B
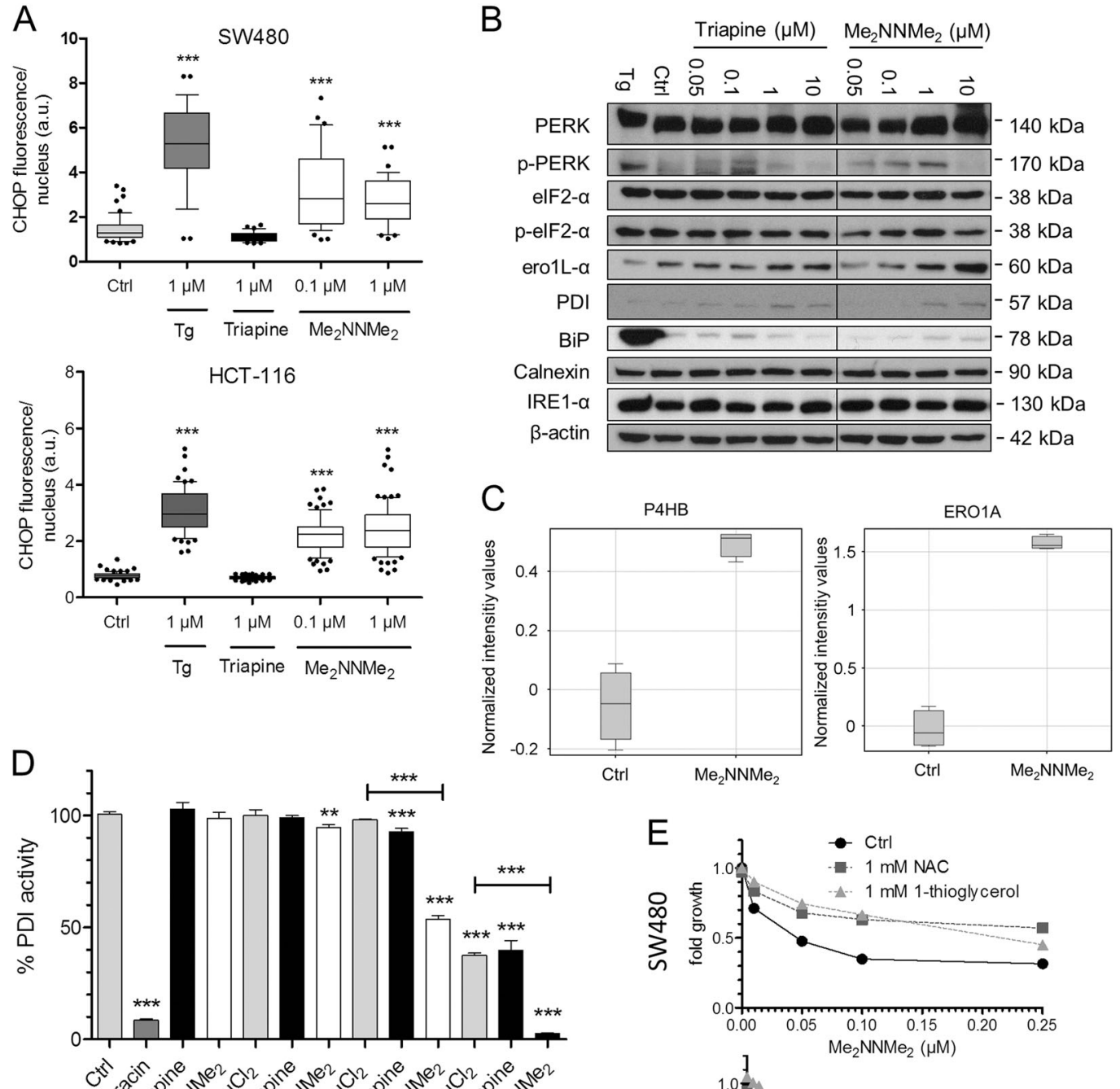

E

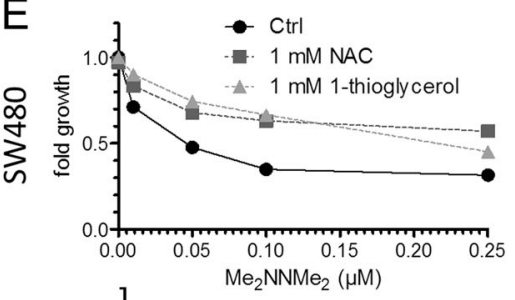

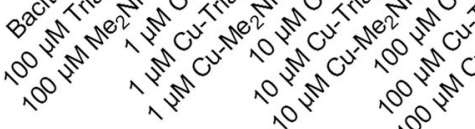

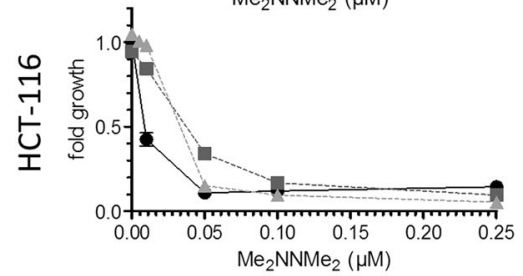

F

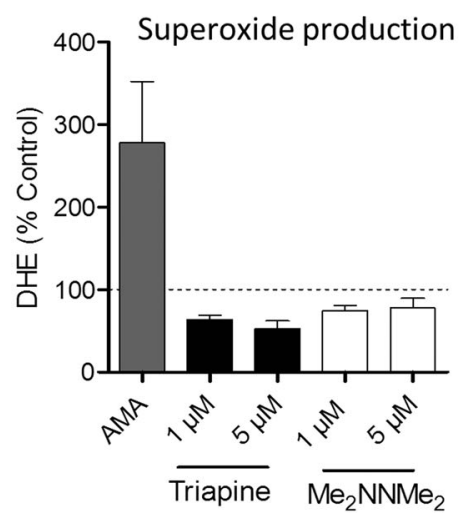

G

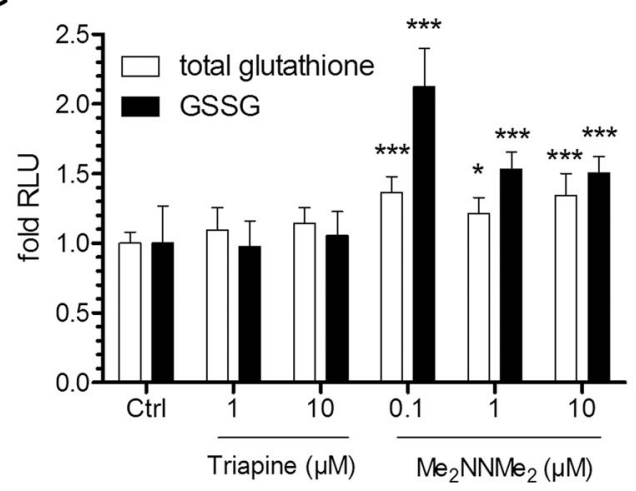

Fig. 7 (See legend on next page.) 
(see figure on previous page)

Fig. 7 ER stress and disruption of thiol redox homeostasis by $\mathrm{Me}_{2} \mathrm{NNMe}_{2}$ treatment. a Quantification of immunofluorescence intensities in the nucleus of the ER stress marker CHOP in SW480 and HCT-116 cells treated with $1 \mu \mathrm{M}$ thapsigargin (Tg), $1 \mu \mathrm{M}$ Triapine or 0.1 and $1 \mu \mathrm{M} \mathrm{Me} \mathrm{NNMe}_{2}$ for $24 \mathrm{~h}$. Values given are the mean intensities \pm the interquartile range and 10 and 90 percentile whiskers of one representative experiment out of three. b Western blot analysis of various ER stress proteins expressed by SW480 cells treated with indicated concentrations of Triapine and $\mathrm{Me}_{2} \mathrm{NNMe}_{2}$ for $24 \mathrm{~h}$. $\beta$-actin was used as a loading control and $\mathrm{Tg}(1 \mu \mathrm{M})$ as positive control for ER stress. c mRNA expression levels for PDI (P4HB) and ero1L-a (ERO1A) in treated $\left(1 \mu \mathrm{M} \mathrm{Me}_{2} \mathrm{NNMe}_{2}\right)$ or untreated SW480 cells were assessed by whole-genome gene expression microarrays. Two independent P4HB oligonucleotides were spotted on the array and gave comparable results. Data for oligonucleotide A_23_P107412 is shown. Normalized values of four replicates indicate upregulation of PDI and ero1L-a mRNA in treated compared to untreated cells. $\mathbf{d}$ PDI reduction activity in the presence of Triapine, $\mathrm{Me}_{2} \mathrm{NNMe}_{2}$ as well as their copper complexes was measured by PROTEOSTAT PDI assay kit. Bacitracin (1 mM) was used as a positive PDI inhibition control. Values given are the mean \pm standard deviation of triplicates of one representative experiment out of two. e Cell viability measured by MTT assay of SW480 or HCT-116 cells after $72 \mathrm{~h}$ treatment of indicated concentrations of $\mathrm{Me}_{2} \mathrm{NNMe}_{2}$ alone as well as in combination with $\mathrm{N}$ acetylcysteine (NAC) or 1-thioglycerol. Values given are the mean \pm standard deviation of triplicates of one representative experiment out of three. $\mathbf{f}$ Superoxide production measured by flow cytometry of DHE fluorescence in HL-60 cells treated with indicated concentrations of Triapine and $\mathrm{Me}_{2} \mathrm{NNMe}_{2}$ for $45 \mathrm{~min}$. Antimycin A (AMA) was used as positive control. g Detection of total and oxidized glutathione (GSSG) by fold increase to control of luminescence in SW480 cells treated with indicated concentrations of Triapine and $\mathrm{Me}_{2} \mathrm{NNMe}_{2}$ for $24 \mathrm{~h}$. Significance to control (or CuCl $)_{2}$ was calculated with one-way ANOVA and Dunnett's multiple comparison test $\left({ }^{* *} p<0.001,{ }^{* *} p \leq 0.01,{ }^{*} p \leq 0.05\right)$

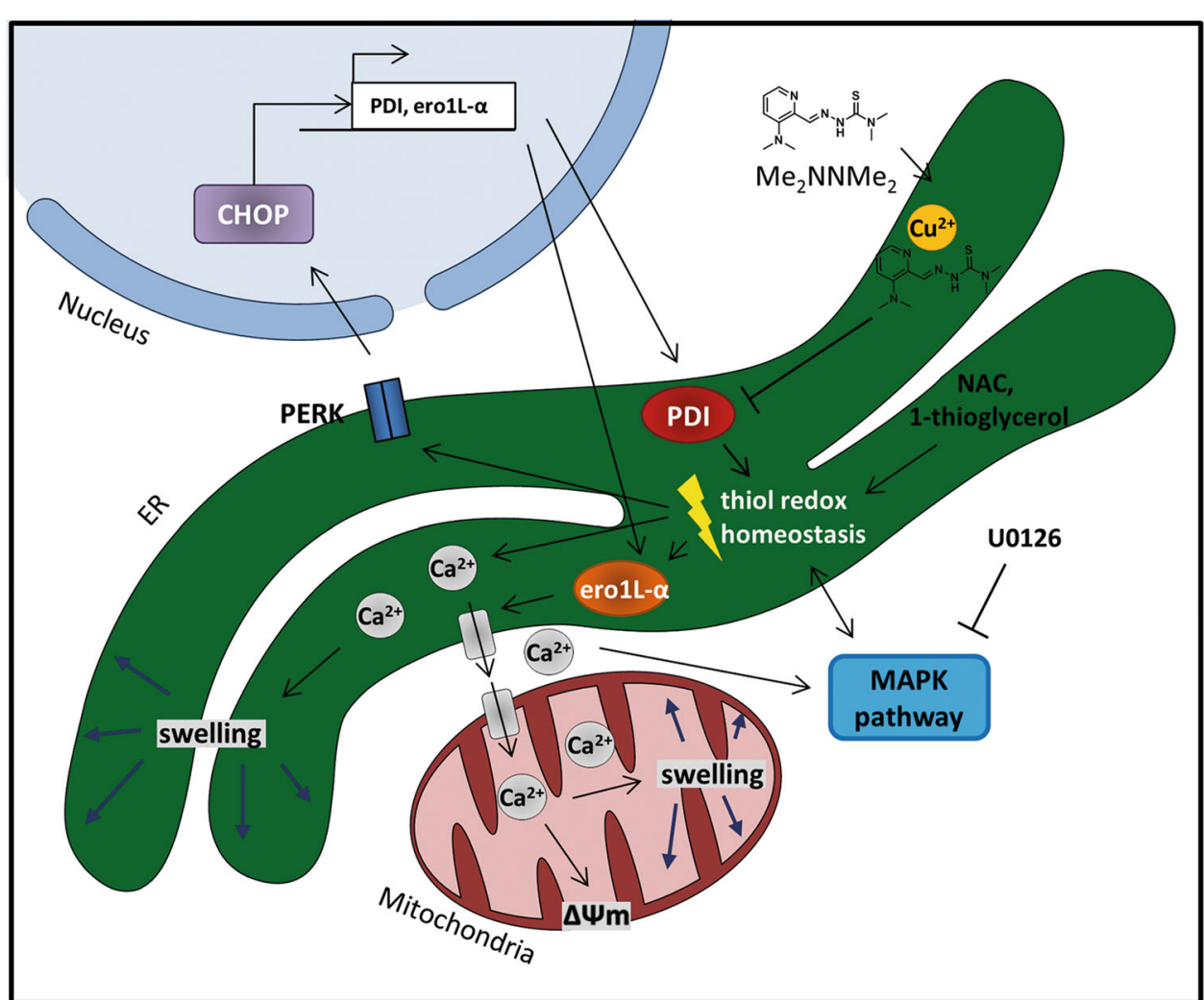

Fig. 8 Proposed mechanism of $\mathrm{Me}_{2} \mathrm{NNMe}_{2}$-induced paraptosis. $\mathrm{Me}_{2} \mathrm{NNMe}_{2}$ accumulates in the ER, where it inhibits the reductive potential of PDI. This leads to the disruption of the ER thiol redox homeostasis, which in turn activates PERK signaling and release of $\mathrm{Ca}^{2+}$ ions from the ER. While PERK activation is followed by CHOP translocation into the nucleus and increased transcription of PDI and ero $1 \mathrm{~L}-\mathrm{a}$, released $\mathrm{Ca}^{2+}$ ions are taken up by mitochondria. Prolonged $\mathrm{Ca}^{2+}$ imbalance initiates organelle swelling and mitochondrial membrane depolarization. NAC and 1-thioglycerol can ameliorate thiol redox imbalances. MAPKs further regulate $\mathrm{Ca}^{2+}$ and thiol redox homeostasis, which can be inhibited by U0126

enhanced mitochondrial $\mathrm{Ca}^{2+}$ levels ultimately results in organelle swelling and damage, which explains the excessive depolarization of mitochondria induced by $\mathrm{Me}_{2} \mathrm{NNMe}_{2}$ and many other paraptosis inducers ${ }^{25,27}$.
Noteworthy, we found that BAX knockout resulted in reduced sensitivity to $\mathrm{Me}_{2} \mathrm{NNMe}_{2}$. This could be explained by previously observed lowered $\mathrm{ER} \mathrm{Ca}^{2+}$ stores in BAX-deficient cells, which led to reduced $\mathrm{Ca}^{2+}$ uptake 
by mitochondria after release from the $\mathrm{ER}^{47}$. In addition, also a link between PDI and BAX/BAK signaling has already been reported ${ }^{48}$. Nevertheless, why this mitochondrial damage in the course of paraptosis does not activate the intrinsic (mitochondrial) pathway of apoptosis is still a matter of discussion and warrants further investigations.

Taken together, in the here presented study, we identified paraptosis induction via disruption of the ER thiol redox homeostasis as a new mode of action in the activity of the highly active nanomolar TSC $\mathrm{Me}_{2} \mathrm{NNMe}_{2}$ and possibly also for other nanomolar TSCs such as $\mathrm{DpC}, \mathrm{Dp} 44 \mathrm{mT}$, and Coti-2. Moreover, we suggest the ER-resident PDI as possible new target for members of this compound class, which could make them interesting candidates for the treatment of cancers with deficiencies in apoptosis induction.

\section{Materials and methods Reagents}

Triapine and $\mathrm{Me}_{2} \mathrm{NNMe}_{2}$ were synthesized as previously described ${ }^{11,49}$. U0126 was purchased from Calbiochem, z-VAD-FMK from Enzo Life Sciences (New York, USA), 1-thioglycerol, thapsigargin, antimycin A, NAC, PD98059, trametinib and selumetinib from Selleck Chemicals (TX, USA). All other chemicals were from Sigma-Aldrich.

\section{Cell culture}

The following human cell models were used in this study: the colon carcinoma cell lines SW480 (obtained from the American Tissue Culture Collection) as well as HCT-116 and its respective subline with BAX knockout (obtained from B. Vogelstein, John Hopkins University, Baltimore $^{18}$ ). SW480 cells were cultured in MEME and HCT-116 cell lines in McCoy's 5a Medium (from SigmaAldrich, MO, USA). The cells were cultivated in medium containing 10\% fetal calf serum (FCS, PAA, Linz, Austria).

\section{Transfection}

SW480 cells were plated $\left(3 \times 10^{5}\right.$ cells/well $)$ in 6 -well plates and allowed to recover for $24 \mathrm{~h}$. Transfection of pEYFP-ER expression plasmid (\#632355, Clontech laboratories, USA) encoding a YFP fused to the ERtargeting sequence of calreticulin at the $5^{\prime}$-end and the ER retention sequence KDEL at the $3^{\prime}$-end or with a control plasmid was performed using Lipofectamine 2000 reagent (Invitrogen, CA, USA) according to the manufacturers' instructions. Medium was changed after $5 \mathrm{~h}$ and selection medium containing $1.2 \mathrm{mg} / \mathrm{ml} \mathrm{G} 418$ was added $24 \mathrm{~h}$ after transfection. Expression of YFP in the ER was investigated $48 \mathrm{~h}$ later.

\section{Cell viability assay}

The cells were plated $\left(2 \times 10^{3}\right.$ cells/well $)$ in 96-well plates and allowed to recover for $24 \mathrm{~h}$. Then, cells were treated with Triapine or $\mathrm{Me}_{2} \mathrm{NNMe}_{2}$. In combination treatments, the modulator was always added $1 \mathrm{~h}$ in advance. Cell viability was measured by the 3-(4,5-dimethylthiazol-2-yl)-2,5-diphenyltetrazolium bromide (MTT)-based vitality assay (EZ4U; Biomedica, Vienna, Austria) as published ${ }^{50}$. GraphPad Prism software was used to calculate cell viability expressed as $\mathrm{IC}_{50}$ values calculated from full dose-response curves.

\section{Fluorescence staining and microscopy}

Cells were seeded into 8-well $\mu$-slides (ibidi $\mathrm{GmbH}$, Germany) with $2 \times 10^{4}$ cells/well and left to recover for $24 \mathrm{~h}$. For organelle tracking, the medium was replaced with serum- and phenol red-free medium with $50 \mathrm{nM}$ MitoTracker Red CMXRos, MitoTracker Green FM or LysoTracker Red (Life technologies, Vienna, Austria). For calcium imaging, cells were incubated with $0.5 \mu \mathrm{M}$ Rhod-2 AM (Abcam, Cambridge, UK) in serum- and phenol red-free medium for $30 \mathrm{~min}$ at $4{ }^{\circ} \mathrm{C}$. After $1 \mathrm{~h}$, cells were washed and imaged with the Nikon Eclipse Ti-e fluorescence microscope with differential interference contrast and RFP or GFP filter settings and a sCMOS pco.edge camera. Life-cell imaging was performed in an environmental chamber pre-heated to $37^{\circ}$ $\mathrm{C}$ with $5 \% \mathrm{CO}_{2}$. For non-fluorescence imaging, phasecontrast pictures were taken with the Nikon Eclipse $\mathrm{Ti}$ inverted microscope with a Nikon DS-Filc camera. Contrast and brightness were adjusted with ImageJ. Cell area was calculated as mean occupied area per cell from at least two different sections in one well at the end of life-cell imaging $(48 \mathrm{~h})$ using ImageJ and then normalized to control.

\section{CHOP immunofluorescence}

Cells $\left(2 \times 10^{4} /\right.$ well $)$ were seeded in 8 -well chamber slides (ibidi $\mathrm{GmbH}$ ). After $24 \mathrm{~h}$ recovery, cells were treated with indicated drug concentrations and fixed with $4 \%$ paraformaldehyde for $15 \mathrm{~min}$ at room temperature and (after washing with PBS) blocked and permeabilized with 5\% FCS, $0.3 \%$ Triton X-100 in PBS for $1 \mathrm{~h}$. The primary antibody CHOP (Cell Signaling Technology) was added $1: 3200$ in $1 \%$ BSA and $0.3 \%$ Triton X-100 in PBS overnight at $4{ }^{\circ} \mathrm{C}$. After washing with PBS, the cells were incubated with anti-mouse secondary antibody conjugated to AlexaFluor488 (Thermo Fisher, 1:500 in 1\% BSA and $0.3 \%$ Triton X-100 in PBS) for $1 \mathrm{~h}$. Cells were again washed and counterstained with 4',6-diamidine-2'phenylindole dihydrochloride (DAPI; $1 \mu \mathrm{g} / \mathrm{ml}$ ) and wheat germ agglutinin (WGA, $10 \mu \mathrm{g} / \mathrm{ml}$, Vector Laboratories, 
CA, USA) in PBS for $10 \mathrm{~min}$. The dyes were removed, and the cells mounted in Vectashield mounting medium (Vector Laboratories, CA, USA) with a coverslip. Images were taken with a Zeiss LSM 700 Olympus (Carl Zeiss AG, Oberkochen, Germany) confocal microscope and $\mathrm{CHOP}$ fluorescence intensities per nucleus were measured using ImageJ.

\section{Annexin V/PI stain and detection of mitochondrial membrane potential}

Briefly, $2 \times 10^{5}$ cells/well were seeded in 6-well plates. After $24 \mathrm{~h}$ recovery, cells were treated for another $24 \mathrm{~h}$ with the indicated drug concentrations. Then, cells were either stained with annexin V-APC (AV) and propidium iodide (PI) or with $10 \mu \mathrm{g} / \mathrm{ml} \mathrm{JC-1}$ as previously described $^{51,52}$.

\section{Protein expression}

After drug treatment, total protein lysates were prepared, separated by SDS-PAGE and transferred onto a polyvinylidene difluoride membrane for Western blotting as described previously ${ }^{50}$. The following antibodies were used: Cell Signaling Technology (MA, USA): BAX (\#5023), Bcl- $x_{\mathrm{L}}$ (\#2764), PERK (\#5683), phospho-PERK (Thr980, \#3179), Calnexin (\#2679), eIF2- $\alpha$ (\#5324), phospho-eIF2- $\alpha$ (Ser51, \#3398), PDI (\#3501), ero1L- $\alpha$ (\#3264), BiP (\#3177), IRE1 $\alpha$ (\#3294), MEK1/2 (\#9126), phospho-MEK1/2 (Ser217/221, \#9154), MEK2 (\#9125) ERK1/2 (\#4695), phospho-ERK1/2 (Thr202/Tyr204, \#4370). Sigma-Aldrich: $\beta$-actin (AC-15; \#A1978). Primary antibodies were used 1:1000. Secondary, anti-mouse (\#7076) and anti-rabbit (\#7074) horseradish peroxidaselabeled antibodies from Cell Signaling Technologies were used in working dilutions of 1:10,000.

\section{Gene knockdown by siRNA}

Cells were transfected with Xfect ${ }^{\mathrm{TM}}$ RNA Transfection Reagent (Clontech Laboratories, CA, USA) using siRNA against MEK2 (Dharmacon, \#M-003573-03-0005) or nontargeting siRNA (Dharmacon, \#D-001206-13-05) following the manufacturer's recommendations. Briefly, $3 \times 10^{5}$ SW480 cells/well or $4 \times 10^{5}$ HCT-116 cells/well were seeded in 6-well plates. After $24 \mathrm{~h}$ cells were incubated with the siRNAs and transfection polymer in serum-free medium for $4 \mathrm{~h}$. Then, the medium was exchanged and after another 24 or $48 \mathrm{~h}$ cells were collected for experiments. Efficacy and specificity of gene silencing was verified at the protein level by Western blot following $48 \mathrm{~h}$ siRNA transfection.

\section{Total-RNA isolation and whole-genome gene expression array}

Total RNA from SW480 cells (either untreated or treated for $15 \mathrm{~h}$ ) was isolated using RNeasy Mini kit
(Quiagen) following the manufacturer's instruction. Transcriptional profiles of cells were determined performing a $4 \times 44 \mathrm{~K}$ whole-genome oligonucleotide gene expression array (Agilent) as described previously ${ }^{53}$. Normalization was performed in $\mathrm{R}$ using the Bioconductor (version 3.7) package "limma"54. Wholegenome gene expression array and gene set enrichment analysis (GSEA) were performed as previously described $^{51}$. Visualization of differentially expressed genes in the KEGG database-derived "MAPK signaling pathway" was conducted using the Bioconductor package "pathview" $"$ ".

\section{Raman microspectroscopy}

Cells $\left(2 \times 10^{4}\right.$ /well $)$ were seeded into 8 -well $\mu$-slides with glass-bottom (ibidi GmbH, Germany) and left to recover for $24 \mathrm{~h}$ followed by $24 \mathrm{~h}$ drug treatment. Subsequently, samples were fixed with $2 \%$ formaldehyde in PBS for $5 \mathrm{~min}$. Cells were mapped in PBS using an XploRA INV Raman microscope (Horiba Jobin Yvon, Bensheim, Germany) equipped with a $532 \mathrm{~nm}$ solid state laser at $100 \mathrm{~mW}, 1800 \mathrm{gr} / \mathrm{mm}$ grating and CFI Plan APO $\times 100$ NA 1.4 Oil objective (Nikon). Two spectra per pixel were acquired with an integration time of two seconds in steps of $0.5 \mu \mathrm{m}$ in $\mathrm{X}$ and $\mathrm{Y}$. Cosmic rays were removed automatically. The spectral fingerprint region of $600-1800 \mathrm{~cm}^{-1}$ was extracted from raw spectra, the $1^{\text {st }}$ derivative ( size $=5$, degree $=1$ ) was calculated and unit vector normalization was performed. Principal component analysis (PCA) with three components was computed and displayed as a spectral map. Component spectra were shifted on the intensity scale for better visualization. The spectrum of $\mathrm{Me}_{2} \mathrm{NNMe}_{2}$ powder was acquired using the $532 \mathrm{~nm}$ laser at $100 \mathrm{~mW}, 2400 \mathrm{gr} /$ $\mathrm{mm}$ grating, CFI Apo Lambda $\mathrm{S} \times 40$ NA 1.15 Water objective (Nikon) with $4 \times 5 \mathrm{~s}$ integration and processed as described above. The processed spectrum of $\mathrm{Me}_{2} \mathrm{NNMe}_{2}$ was fitted to the spectral map of the cells by using the CLS function. All calculation and visualization steps were performed in LabSpec 6 (Horiba, Jobin Yvon, Bensheim, Germany).

\section{PDI reduction activity measurement}

PDI reduction activity was measured using PROTEOSTAT PDI assay kit (\#ENZ-51024, Enzo Life Sciences, Lausen, Switzerland). Experiments were performed according to the manufacturer's instructions. Briefly, drugs alone or preincubated with $\mathrm{CuCl}_{2}$ (1:1) were added to a prepared insulin PDI solution. Then, DTT was added to start PDI reduction activity. After $30 \mathrm{~min}$ the reaction was stopped by the Stop reagent and the insulin precipitate was fluorescently labeled with Proteostat PDI detection reagent for $15 \mathrm{~min}$. Fluorescence intensity was measured at $500 \mathrm{~nm}$ excitation and $603 \mathrm{~nm}$ emission 
using the spectrophotometer Tecan infinite 200Pro (Tecan Group, Männedorf, Switzerland).

\section{Glutathione measurement}

Cells were plated $\left(4 \times 10^{3}\right.$ cells/well $)$ in 96 -well plates and allowed to recover for $24 \mathrm{~h}$. Then, cells were treated in sextuplicates with Triapine or $\mathrm{Me}_{2} \mathrm{NNMe}_{2}$ for another $24 \mathrm{~h}$. Cells were lysed and levels of total and oxidized glutathione were measured in triplicates with GSH/ GSSG-Glo $^{\mathrm{TM}}$ Assay (\#V6611, Promega, Madison, USA) according to the manufacturer's instructions. Fold increase in relative luminescence units (RLU) was calculated compared to untreated control after subtraction of cell-free blank.

\section{Detection of intracellular superoxide}

Dihydroethidium (DHE, \#D7008, Sigma-Aldrich, MO, USA) was used to detect the production of intracellular superoxide. Briefly, $5 \times 10^{5} \mathrm{HL}-60$ cells per sample in 500 $\mu \mathrm{l}$ of PBS $\left(78.1 \mathrm{mM} \mathrm{Na} \mathrm{PO}_{4} \times 2 \mathrm{H}_{2} \mathrm{O}, 14.7 \mathrm{mM} \mathrm{KH}_{2} \mathrm{PO}_{4}\right.$, $26.8 \mathrm{mM} \mathrm{KCl}, 1.37 \mathrm{M} \mathrm{NaCl}$ ) were incubated with indicated concentrations of Triapine and $\mathrm{Me}_{2} \mathrm{NNMe}_{2}$ for 45 min. Subsequently, DHE $(10 \mu \mathrm{M})$ was added $15 \mathrm{~min}$ after the compounds. After incubation, the mean fluorescence intensity was measured by flow cytometry using a FACSCalibur instrument (Becton Dickinson, Palo Alto, CA, USA). Antimycin A (AMA, $10 \mu \mathrm{M})$ was used as positive control.

\section{Acknowledgements}

This work was performed within the Research Cluster "Translational Cancer Therapy Research" Vienna. This work was in part funded by the Austrian Science Fund (FWF) grant number P22072 (to Walter Berger), number P31923 (to Christian R. Kowol) and number P26603 (to Petra Heffeter). The funding sources had no involvement in collection, analysis and interpretation of data as well as in the decision to submit the article for publication. S.H. is a recipient of a DOC Fellowship of the Austrian Academy of Sciences. We are indebted to Sushilla van Schoonhoven and Mirjana Stojanovic for competent technical assistance. Furthermore, we are grateful to Irene Herbacek for fluorescenceactivated cell sorting analysis and Gerald Timelthaler for the assistance in confocal microscopy. We thank the BOKU-VIBT Imaging Center for technical support with Raman microspectroscopy.

\section{Author details}

${ }^{1}$ Institute of Cancer Research and Comprehensive Cancer Center, Department of Medicine I, Medical University of Vienna, Borschkegasse 8a, A-1090 Vienna, Austria. ${ }^{2}$ Research Cluster "Translational Cancer Therapy Research", Vienna, Austria. ${ }^{3}$ Institute of Inorganic Chemistry, Faculty of Chemistry, University of Vienna, Waehringer Str. 42, A-1090 Vienna, Austria. ${ }^{4}$ Department of Biotechnology, BOKU-University of Natural Resources and Life Sciences, ViennaMuthgasse 18, A-1190 Vienna, Austria. ${ }^{5}$ Christian Doppler Laboratory on Biotechnology of Skin Aging, Muthgasse 18, A-1190 Vienna, Austria. ${ }^{6}$ Evercyte GmbH, Muthgasse 18, A-1190 Vienna, Austria. ${ }^{7}$ Department of Internal Medicine I and Comprehensive Cancer Center, Medical University of Vienna, Lazarettgasse 14, A-1090 Vienna, Austria. ${ }^{8}$ Department of Physiology, Faculty of Medicine, Semmelweis University, Tűzoltó utca 37-47, H-1094 Budapest, Hungary. ${ }^{9}$ Institute of Enzymology, Research Centre for Natural Sciences, Hungarian Academy of Sciences, Magyar Tudósok körútja 2, H-1117 Budapest, Hungary. ${ }^{10}$ Science Consult DI Thomas Mohr KG, Enzianweg 10a, A-2353 Guntramsdorf, Austria
Conflict of interest

The authors declare that they have no conflict of interest.

\section{Publisher's note}

Springer Nature remains neutral with regard to jurisdictional claims in published maps and institutional affiliations.

Supplementary Information accompanies this paper at (https://doi.org/ 10.1038/s41419-018-1102-z).

Received: 13 August 2018 Revised: 4 September 2018 Accepted: 21 September 2018

Published online: 15 October 2018

References

1. Kalinowski, D. S., Quach, P. \& Richardson, D. R. Thiosemicarbazones: the new wave in cancer treatment. Future Med. Chem. 1, 1143-1151 (2009).

2. Heffeter, P. et al. Anticancer thiosemicarbazones: chemical properties, interaction with iron metabolism, and resistance development. Antioxid. Redox Signal. https://doi.org/10.1089/ars.2017.7487 (2018).

3. Giles, F. J. et al. Phase I and pharmacodynamic study of Triapine, a novel ribonucleotide reductase inhibitor, in patients with advanced leukemia. Leuk. Res. 27, 1077-1083 (2003).

4. Karp, J. E. et al. A phase I study of the novel ribonucleotide reductase inhibitor 3-aminopyridine-2-carboxaldehyde thiosemicarbazone (3-AP, Triapine) in combination with the nucleoside analog fludarabine for patients with refractory acute leukemias and aggressive myeloproliferative disorders. Leuk. Res. 32, 71-77 (2008)

5. Yee, K. W. et al. Triapine and cytarabine is an active combination in patients with acute leukemia or myelodysplastic syndrome. Leuk. Res. 30, 813-822 (2006).

6. Zeidner, J. F. et al. A phase $\|$ trial of sequential ribonucleotide reductase inhibition in aggressive myeloproliferative neoplasms. Haematologica 99, 672-678 (2014).

7. Attia, S. et al. A phase 2 consortium (P2C) trial of 3-aminopyridine-2carboxaldehyde thiosemicarbazone (3-AP) for advanced adenocarcinoma of the pancreas. Invest. New Drugs 26, 369-379 (2008).

8. Knox, J. J. et al. Phase II study of Triapine in patients with metastatic renal cell carcinoma: a trial of the National Cancer Institute of Canada Clinical Trials Group (NCIC IND.161). Invest. New Drugs 25, 471-477 (2007).

9. Jansson, P. J., Sharpe, P. C., Bernhardt, P. V. \& Richardson, D. R. Novel thiosemicarbazones of the ApT and DpT series and their copper complexes: identification of pronounced redox activity and characterization of their antitumor activity. J. Med. Chem. 53, 5759-5769 (2010).

10. Maleki Vareki, S., Salim, K. Y., Danter, W. R. \& Koropatnick, J. Novel anti-cancer drug COTI-2 synergizes with therapeutic agents and does not induce resistance or exhibit cross-resistance in human cancer cell lines. PLoS ONE 13, e0191766 (2018).

11. Kowol, C. R. et al. Impact of stepwise $\mathrm{NH}_{2}$-methylation of triapine on the physicochemical properties, anticancer activity, and resistance circumvention. J. Med. Chem. 59, 6739-6752 (2016).

12. Ishiguro, K. et al. Distinct mechanisms of cell-kill by triapine and its terminally dimethylated derivative Dp44mT due to a loss or gain of activity of their copper(II) complexes. Biochem. Pharmacol. 91, 312-322 (2014).

13. Lovejoy, D. B. et al. Antitumor activity of metal-chelating compound Dp44mT is mediated by formation of a redox-active copper complex that accumulates in lysosomes. Cancer Res. 71, 5871-5880 (2011).

14. Seebacher, N. A., Richardson, D. R. \& Jansson, P. J. A mechanism for overcoming P-glycoprotein-mediated drug resistance: novel combination therapy that releases stored doxorubicin from lysosomes via lysosomal permeabilization using Dp44mT or DpC. Cell Death Dis. 7, e2510 (2016).

15. Sperandio, S., de Belle, I. \& Bredesen, D. E. An alternative, nonapoptotic form of programmed cell death. Proc. Natl Acad. Sci. USA 97, 14376-14381 (2000).

16. Lee, D., Kim, I. Y., Saha, S. \& Choi, K. S. Paraptosis in the anti-cancer arsenal of natural products. Pharmacol. Ther. 162, 120-133 (2016). 
17. Gandin, V. et al. Therapeutic potential of the phosphino $\mathrm{Cu}(\mathrm{l})$ complex (HydroCuP) in the treatment of solid tumors. Sci. Rep. 7, 13936 (2017).

18. Chen, $\mathrm{X}$. et al. Hinokitiol copper complex inhibits proteasomal deubiquitination and induces paraptosis-like cell death in human cancer cells. Eur. J. Pharmacol. 815, 147-155 (2017).

19. Tardito, S. et al. The thioxotriazole copper(II) complex A0 induces endoplasmic reticulum stress and paraptotic death in human cancer cells. J. Biol. Chem. 284, 24306-24319 (2009)

20. Movasaghi, Z., Rehman, S. \& Rehman, I. U. Raman spectroscopy of biological tissues. Appl. Spectrosc. Rev. 42, 493-541 (2007).

21. Xue, J. et al. Morusin induces paraptosis-like cell death through mitochondrial calcium overload and dysfunction in epithelial ovarian cancer. Chem. Biol. Interact. 283, 59-74 (2018).

22. Yoon, M. J. et al. Release of $\mathrm{Ca} 2+$ from the endoplasmic reticulum and its subsequent influx into mitochondria trigger celastrol-induced paraptosis in cancer cells. Oncotarget 5, 6816-6831 (2014).

23. Bury, $M$. et al. Ophiobolin A induces paraptosis-like cell death in human glioblastoma cells by decreasing BKCa channel activity. Cell Death Dis. 4, e561 (2013).

24. Heath-Engel, H. M., Wang, B. \& Shore, G. C. Bcl2 at the endoplasmic reticulum protects against a Bax/Bak-independent paraptosis-like cell death pathway initiated via p20Bap31. Biochim. Biophys. Acta 1823, 335-347 (2012).

25. Yoon, M. J. et al. Stronger proteasomal inhibition and higher $\mathrm{CHOP}$ induction are responsible for more effective induction of paraptosis by dimethoxycurcumin than curcumin. Cell Death Dis. 5, e1112 (2014)

26. He, L. et al. Cyclometalated iridium(iii) complexes induce mitochondriaderived paraptotic cell death and inhibit tumor growth in vivo. Dalton Trans. https://doi.org/10.1039/c8dt00783g (2018).

27. Garrido-Armas, M. et al. Paraptosis in human glioblastoma cell line induced by curcumin. Toxicol. In Vitro https://doi.org/10.1016/j.tiv.2018.04.014 (2018).

28. Kim, I. Y. et al. Ophiobolin A kills human glioblastoma cells by inducing endoplasmic reticulum stress via disruption of thiol proteostasis. Oncotarget $\mathbf{8}$, 106740-106752 (2017).

29. Nedungadi, D. et al. 6-Shogaol induces caspase-independent paraptosis in cancer cells via proteasomal inhibition. Exp. Cell Res. 364, 243-251 (2018).

30. Narindrasorasak, S., Yao, P. \& Sarkar, B. Protein disulfide isomerase, a multifunctional protein chaperone, shows copper-binding activity. Biochem. Biophys. Res. Commun. 311, 405-414 (2003).

31. Laurindo, F. R., Pescatore, L. A. \& Fernandes Dde, C. Protein disulfide isomerase in redox cell signaling and homeostasis. Free Radic. Biol. Med. 52, 1954-1969 (2012).

32. Housman, G. et al. Drug resistance in cancer: an overview. Cancers 6 , 1769-1792 (2014).

33. Wang, L., Gundelach, J. H. \& Bram, R. J. Cycloheximide promotes paraptosis induced by inhibition of cyclophilins in glioblastoma multiforme. Cell Death Dis. 8, e2807 (2017)

34. Li, G. et al. Role of ERO1-alpha-mediated stimulation of inositol 1,4,5-triphosphate receptor activity in endoplasmic reticulum stress-induced apoptosis. J. Cell Biol. 186, 783-792 (2009).

35. Kalinowski, D. S. et al. Redox cycling metals: pedaling their roles in metabolism and their use in the development of novel therapeutics. Biochim. Biophys. Acta 1863, 727-748 (2016).

36. Lane, D. J. et al. Expanding horizons in iron chelation and the treatment of cancer: role of iron in the regulation of ER stress and the epithelialmesenchymal transition. Biochim. Biophys. Acta 1845, 166-181 (2014).
37. Crenshaw, T. R. \& Cory, J. G. Overexpression of protein disulfide isomerase-like protein in a mouse leukemia L1210 cell line selected for resistance to 4methyl-5-amino-1-formylisoquinoline thiosemicarbazone, a ribonucleotide reductase inhibitor. Adv. Enzym. Regul. 42, 143-157 (2002).

38. Kranz, P. et al. PDI is an essential redox-sensitive activator of PERK during the unfolded protein response (UPR). Cell Death Dis. 8, e2986 (2017).

39. Darling, N. J. \& Cook, S. J. The role of MAPK signalling pathways in the response to endoplasmic reticulum stress. Biochim. Biophys. Acta 1843, 2150-2163 (2014)

40. Li, Y., Guo, Y., Tang, J., Jiang, J. \& Chen, Z. New insights into the roles of CHOPinduced apoptosis in ERstress. Acta Biochim. Biophys. Sin. 46, 629-640 (2014).

41. Marciniak, S. J. et al. CHOP induces death by promoting protein synthesis and oxidation in the stressed endoplasmic reticulum. Genes Dev. 18, 3066-3077 (2004).

42. Ubeda, M. \& Habener, J. F. CHOP gene expression in response to endoplasmic-reticular stress requires NFY interaction with different domains of a conserved DNA-binding element. Nucleic Acids Res. 28, 4987-4997 (2000).

43. Singha, P. K., Pandeswara, S., Venkatachalam, M. A. \& Saikumar, P. Manumycin A inhibits triple-negative breast cancer growth through LC3-mediated cytoplasmic vacuolation death. Cell Death Dis. 4, e457 (2013).

44. Tadic, V., Prell, T., Lautenschlaeger, J. \& Grosskreutz, J. The ER mitochondria calcium cycle and ER stress response as therapeutic targets in amyotrophic lateral sclerosis. Front. Cell. Neurosci. 8, 147 (2014).

45. Bhandary, B., Marahatta, A., Kim, H. R. \& Chae, H. J. An involvement of oxidative stress in endoplasmic reticulum stress and its associated diseases. Int. J. Mol. Sci. 14, 434-456 (2012).

46. Hacker, K. \& Medler, K. F. Mitochondrial calcium buffering contributes to the maintenance of Basal calcium levels in mouse taste cells. J. Neurophysiol. 100 2177-2191 (2008).

47. Scorrano, L. et al. BAX and BAK regulation of endoplasmic reticulum Ca2+: a control point for apoptosis. Science 300, 135-139 (2003).

48. Hoffstrom, B. G. et al. Inhibitors of protein disulfide isomerase suppress apoptosis induced by misfolded proteins. Nat. Chem. Biol. 6, 900-906 (2010).

49. Kowol, C. R. et al. Impact of metal coordination on cytotoxicity of 3 aminopyridine-2-carboxaldehyde thiosemicarbazone (triapine) and novel insights into terminal dimethylation. J. Med. Chem. 52, 5032-5043 (2009).

50. Heffeter, P. et al. Intrinsic and acquired forms of resistance against the anticancer ruthenium compound KP1019 [indazolium trans-[tetrachlorobis $(1 \mathrm{H}$ indazole)ruthenate (III)] (FFC14A). J. Pharmacol. Exp. Ther. 312, 281-289 (2005).

51. Englinger, B. et al. Loss of CUL4A expression is underlying cisplatin hypersensitivity in colorectal carcinoma cells with acquired trabectedin resistance. Br. J. Cancer 116, 489-500 (2017).

52. Trondl, R. et al. Triapine and a more potent dimethyl derivative induce endoplasmic reticulum stress in cancer cells. Mol. Pharmacol. 85, 451-459 (2014).

53. Laszlo, V. et al. Epigenetic down-regulation of integrin alpha7 increases migratory potential and confers poor prognosis in malignant pleural mesothelioma. J. Pathol. 237, 203-214 (2015).

54. Ritchie, M. E. et al. limma powers differential expression analyses for RNAsequencing and microarray studies. Nucleic Acids Res. 43, e47 (2015).

55. Luo, W. \& Brouwer, C. Pathview: an R/Bioconductor package for pathwaybased data integration and visualization. Bioinformatics 29, 1830-1831 (2013). 